\title{
Third-line therapy for chronic myeloid leukemia: current status and future directions
}

\author{
Jorge Cortes ${ }^{1 *}$ (ID and Fabian Lang ${ }^{2}$
}

\begin{abstract}
Chronic myeloid leukemia (CML) is driven by the BCR-ABL1 fusion protein, formed by a translocation between chromosomes 9 and 22 that creates the Philadelphia chromosome. The BCR-ABL1 fusion protein is an optimal target for tyrosine kinase inhibitors (TKIs) that aim for the adenosine triphosphate (ATP) binding site of ABL1. While these drugs have greatly improved the prognosis for $C M L$, many patients ultimately fail treatment, some requiring multiple lines of TKI therapy. Mutations can occur in the ATP binding site of ABL1, causing resistance by preventing the binding of many of these drugs and leaving patients with limited treatment options. The approved TKIs are also associated with adverse effects that may lead to treatment discontinuation in some patients. Efficacy decreases with each progressive line of therapy; data suggest little clinical benefit of treatment with a third-line (3L), second-generation tyrosine kinase inhibitor (2GTKI) after failure of a first-generation TKI and a 2GTKI. Novel treatment options are needed for the patient population that requires treatment in the $3 \mathrm{~L}$ setting and beyond. This review highlights the need for clear guidelines and new therapies for patients requiring $3 \mathrm{~L}$ treatment and beyond.
\end{abstract}

Keywords: Chronic myeloid leukemia, Third line, Tyrosine kinase inhibitors, Emerging therapies

\section{Introduction}

Chronic myeloid leukemia (CML) is characterized by the presence of the Philadelphia $(\mathrm{Ph})$ chromosome formed by a balanced translocation between chromosomes 9 and 22, leading to formation of a $B C R-A B L 1$ fusion gene [1]. The resultant constitutively active BCR-ABL1 fusion oncoprotein drives the pathogenesis of CML [2]. The advent of tyrosine kinase inhibitors (TKIs), which target the adenosine triphosphate (ATP) binding site of ABL1, has transformed CML into a chronic disease; many patients achieve a life expectancy close to that of the general population [3]. Treatment and response recommendations currently focus on first-line (1L) and second-line (2L) therapy; $1 \mathrm{~L}$ treatment is usually a first-generation (imatinib) or second-generation (2G; nilotinib, dasatinib, or bosutinib) TKI, as outlined in the National

\footnotetext{
*Correspondence: jorge.cortes@augusta.edu

${ }^{1}$ Georgia Cancer Center at Augusta University, 1410 Laney Walker Rd., CN2222, Augusta, GA 30912, USA
}

Full list of author information is available at the end of the article
Comprehensive Cancer Network (NCCN) guidelines and European LeukemiaNet (ELN) recommendations $[4,5]$. As treatments have advanced over time, treatment goals have evolved from improving survival, preventing progression, and reducing treatment-related toxicities to treatment-free remission (TFR); however, some patients fail to meet these goals with the use of existing approved therapies [4-9]. Patients who achieve a sustained deep molecular response (DMR) on TKI therapy may be eligible for TFR $[8,9]$. For patients who are not eligible for TFR, DMR is still an important treatment goal, as DMR has been associated in some studies with improved overall survival (OS) [10]. However, a significant proportion of patients fail to reach sustained DMR. Among patients with CML in chronic phase (CML-CP), over $50 \%$ of patients treated with imatinib eventually develop resistance or intolerance [11, 12]. For 2GTKIs, when used as frontline therapy, approximately $30-40 \%$ of patients need to change therapy by 5 years [13-15]. By 5 years, only $\approx 30 \%$ of patients treated with imatinib and original author(s) and the source, provide a link to the Creative Commons licence, and indicate if changes were made. The images or other third party material in this article are included in the article's Creative Commons licence, unless indicated otherwise in a credit line to the material. If material is not included in the article's Creative Commons licence and your intended use is not permitted by statutory regulation or exceeds the permitted use, you will need to obtain permission directly from the copyright holder. To view a copy of this licence, visit http://creativecommons.org/licenses/by/4.0/. The Creative Commons Public Domain Dedication waiver (http://creativeco mmons.org/publicdomain/zero/1.0/) applies to the data made available in this article, unless otherwise stated in a credit line to the data. 
30-55\% treated with 2GTKIs achieved a 4.5-log molecular response $\left(\mathrm{MR}^{4.5}, B C R-A B L 1^{\mathrm{IS}} \leq 0.0032 \%\right)$ [15-17].

While clear guidelines exist for $1 \mathrm{~L}$ and $2 \mathrm{~L}$ therapies, treatment beyond $2 \mathrm{~L}$ is poorly established as few studies have prospectively addressed this scenario [4, 5]. Patients with treatment failure/resistance to $2 \mathrm{~L}$ therapy have limited options and exhibit poor responses to additional treatment, with few achieving DMR [5, 18-23]. An unmet need exists for more efficacious third-line (3L) options for patients resistant or intolerant to TKIs.

\section{Unmet needs in the $\mathbf{3 L}+$ setting}

Many patients with CML are at risk of disease progression; sequential TKI use is associated with a decreased probability of response and worse OS. By 5 years, $30-50 \%$ of patients discontinue imatinib, with $5-7 \%$ discontinuing due to intolerance and $15-20 \%$ due to resistance [16, 17]. Patients with poorer molecular responses to imatinib are at a higher risk of progression and death [10]. Resistance rates are even higher during $2 \mathrm{~L}$ treatment, with $60-70 \%$ of patients failing to achieve a major molecular response (MMR) and $50-56 \%$ of patients failing to achieve a complete cytogenetic response (CCyR) with 2 years of follow-up (Table 1) [14, 24-26]. Patients with failure on 3L TKI therapy have higher rates of progression and death $[11,18,19,27]$.

Current TKIs have off-target activities due to their lack of specificity, which can lead to long-term safety issues and intolerance, and $2-24 \%$ of patients discontinue therapy because of adverse events (AEs) due to on- or off-target effects [11, 14, 16-19, 27-32]. Despite management of therapy-related AEs with dose reductions, transient treatment interruptions, supportive care, and concomitant medications, many patients treated with $\geq 2$ TKIs are still at higher risk of experiencing TKI intolerance [33]. Cross-intolerance is uncommon in patients treated with TKIs, with the possible exception of myelosuppression, which is reported more frequently; however, patients may experience different AEs upon switching therapy [34-37]. As is the case with resistance, for patients with intolerance to $2 \mathrm{~L}$ therapy, there are few remaining options with favorable benefit: risk profiles [38]. Because of limited effective options beyond $2 \mathrm{~L}$, patients may need to continue their $2 \mathrm{~L}$ or $3 \mathrm{~L}$ therapy despite experiencing AEs, frequently at doses not conducive to optimal response.

Sequential treatment with TKIs is frequently accompanied by the emergence of new mutations, resulting in limited sensitivity to the remaining TKIs [39]. The BCR-ABL1 T315I mutation confers resistance to all approved ATP-competitive TKIs, except ponatinib [4, $5,7,40]$. In mutation analyses conducted in a series of studies of patients with imatinib failure with or without prior interferon- $\alpha$, the frequency of T315I mutation was reported to be $10-27 \%$ among patients with a BCRABL1 mutation and 3-15\% overall. In the $2 \mathrm{~L}$ setting, the frequency of T315I mutation was reported in $9-53 \%$ of those with a BCR-ABL1 mutation and in $2-14 \%$ overall [41]. Options for patients with T315I mutations are limited to ponatinib, omacetaxine (only approved in USA), and allogeneic stem cell transplant (allo-SCT). These options have several potential limitations, such as safety concerns, limited efficacy, and adverse impact in quality of life. In addition, other BCR-ABL1 mutations (e.g., T315M and T315V [rare]) or compound mutations (e.g., Y253H/T315I or E255V/T315I) may confer resistance to ponatinib [42-44]. Because of the risk of arterio-occlusive events associated with ponatinib (and other existing TKIs), those with cardiovascular risk factors have even fewer treatment options $[4,5,7,38]$.

\section{Available $3 \mathrm{~L}$ therapies}

The standard-of-care beyond 2L therapy is not well defined by NCCN and ELN guidelines [4, 5, 7]. Upon resistance to and/or intolerance to $2 \mathrm{~L}$ TKIs, any of the remaining TKIs may be used $[4,7]$, although there are limited data, frequently only anecdotal or case series for some of them. The choice of a 3L TKI may depend on a patient's comorbidities, prior AEs, mutation profiles, drug interactions, and compliance issues $[36,45]$.

Ponatinib is a third-generation (3G) TKI approved for patients with CML resistant to $\geq 2$ TKIs and for patients with T315I mutations [38, 46]. Per ELN 2020 recommendations, ponatinib is preferred over an alternative 2GTKI in patients without significant cardiovascular risk factors who are resistant to a 2 GTKI without specific mutations [5].

Omacetaxine, a protein translation inhibitor, is available in the USA for patients who are resistant or intolerant to $\geq 2$ TKIs and does not target the kinase domain of BCR-ABL1 [47, 48]. In a study of 76 highly pretreated patients with CML-CP, $18.4 \%$ experienced a major cytogenetic response $(\mathrm{MCyR})$, with $7.9 \%$ obtaining a CCyR and 3.9\% obtaining a partial cytogenetic response (PCyR) $[49,50]$. In 35 patients with CML in the accelerated phase (AP), $14.3 \%$ obtained a major hematologic response with complete hematologic response $(\mathrm{CHR})$ in $11.4 \%$ and no evidence of leukemia in $2.9 \%[49,50]$. The primary toxicity of omacetaxine is myelosuppression, which can be severe and prolonged.

Allo-SCT remains an important option for patients with CML-CP with failure after $\geq 2$ TKIs $[5,45]$. AlloSCT may also be considered for patients with de novo CML in blast phase (BP), preferably after achieving some response with a TKI-based therapy, in patients with CML-AP who are not responding well to current therapy, 
Table 1 Response rates of $1 \mathrm{~L}$ and $2 \mathrm{~L} \mathrm{TKI}$ therapies ${ }^{\mathrm{a}}$

\begin{tabular}{|c|c|c|c|c|c|}
\hline Study & $\begin{array}{l}\text { Number of } \\
\text { patients, } \mathrm{n}\end{array}$ & Arms & Response & Response rate, n (\%) & $\begin{array}{l}\text { Patients remaining on } \\
\text { study at data cutoff, } \mathrm{n}(\%)\end{array}$ \\
\hline \multicolumn{6}{|l|}{$1 \mathrm{~L}$} \\
\hline \multirow[t]{3}{*}{ Hochhaus A, et al. Leukemia. 2016 [16] } & 283 & Imatinib 400 mg QD & $\begin{array}{l}M M R \text { by } 5 \text { y } \\
M R^{4} \\
M R^{4.5}\end{array}$ & $\begin{array}{l}171(60.4) \\
118(41.7) \\
89(31.4)\end{array}$ & $141(49.8)^{b}$ \\
\hline & 282 & Nilotinib 300 mg BID & $\begin{array}{l}\text { MMR } \\
\mathrm{MR}^{4} \\
\mathrm{MR}^{4.5}\end{array}$ & $\begin{array}{l}217(77.0) \\
185(65.6) \\
151(53.5)\end{array}$ & $169(59.9)$ \\
\hline & 281 & Nilotinib 400 mg BID & $\begin{array}{l}\text { MMR } \\
M^{4} \\
M^{4.5}\end{array}$ & $\begin{array}{l}217(77.2) \\
177(63.0) \\
147(52.3)\end{array}$ & $174(61.9)$ \\
\hline \multirow[t]{2}{*}{ Cortes J, et al. J Clin Oncol. 2016 [17] } & 260 & Imatinib 400 mg QD & $\begin{array}{l}\text { MMR by } 5 \text { y } \\
M^{4.5}\end{array}$ & $\begin{array}{l}(64) \\
(33)\end{array}$ & $162(63)$ \\
\hline & 259 & Dasatinib 100 mg QD & $\begin{array}{l}M M R \\
M R^{4.5}\end{array}$ & $\begin{array}{l}(76) \\
(42)\end{array}$ & $158(61)$ \\
\hline \multirow[t]{2}{*}{ Cortes J, et al. J Clin Oncol. 2018 [14] } & $241^{c}$ & Imatinib 400 mg QD & $\begin{array}{l}M M R \text { at } 2 y \\
M^{4}\end{array}$ & $\begin{array}{l}(50.7) \\
(25.7)\end{array}$ & \\
\hline & 246 & Bosutinib 400 mg QD & $\begin{array}{l}M^{4.5} \\
M M R \\
M^{4} \\
M^{4.5}\end{array}$ & $\begin{array}{l}(10.8) \\
(61.2) \\
(32.8) \\
(13.1)\end{array}$ & \\
\hline \multicolumn{6}{|l|}{$2 \mathrm{~L}$} \\
\hline Kantarjian H, et al. Blood. 2011 [24] & $321^{d}$ & Nilotinib 400 mg BID & $\begin{array}{l}\text { MCyR by } 2 \text { y } \\
\text { MMR }\end{array}$ & $\begin{array}{l}(59)^{e, f} \\
82(28)^{g}\end{array}$ & $124(39)$ \\
\hline \multirow[t]{4}{*}{ Shah N, et al. Haematologica. $2010[25]^{\text {h }}$} & 167 & Dasatinib mg 140 QD & $\begin{array}{l}\text { MCyR by } 2 \text { y } \\
\text { CCyR } \\
\text { MMR }^{i}\end{array}$ & $\begin{array}{l}105(63) \\
84(50) \\
55(38)\end{array}$ & \\
\hline & 167 & Dasatinib 100 mg QD & $\begin{array}{l}\text { MCyR } \\
\text { CCyR } \\
\text { MMR }\end{array}$ & $\begin{array}{l}106(63) \\
83(50) \\
57(37)\end{array}$ & \\
\hline & 168 & Dasatinib 70 mg BID & $\begin{array}{l}\text { MCyR } \\
\text { CCyR } \\
\text { MMR }\end{array}$ & $\begin{array}{l}103(61) \\
90(54) \\
56(38)\end{array}$ & \\
\hline & 168 & Dasatinib 50 mg QD & $\begin{array}{l}\text { MCyR } \\
\text { CCyR } \\
\text { MMR }\end{array}$ & $\begin{array}{l}103(61) \\
84(50) \\
59(38)\end{array}$ & \\
\hline \multirow[t]{2}{*}{$\begin{array}{l}\text { Gambacorti-Passerini C, et al. Am J Hema- } \\
\text { tol. } 2014 \text { [131] }\end{array}$} & 200 & Bosutinib (imatinib resistant) & $\begin{array}{l}\text { MCyR } \\
\text { CCyR }^{j} \\
M^{j} R^{k}\end{array}$ & $\begin{array}{l}108(58) \\
85(46) \\
45(34)\end{array}$ & $92(46)$ \\
\hline & 88 & Bosutinib (imatinib intolerant) & $\begin{array}{l}\text { MCyR' } \\
\text { CCyR } \\
\text { MMR }^{\mathrm{m}}\end{array}$ & $\begin{array}{l}49(61) \\
43(54) \\
24(35)\end{array}$ & $37(42)$ \\
\hline
\end{tabular}

$1 L$ first line, $2 L$ second line, $B I D$ twice a day, CCyR complete cytogenetic response, $M C y R$ major cytogenetic response, $M M R$ major molecular response, $M R^{4} 4.0-$ log molecular response $\left(B C R-A B L 1^{15} \leq 0.01 \%\right), M R^{4.5} 4.5$-log molecular response (BCR-ABL $\left.1^{15} \leq 0.0032 \%\right), Q D$ once a day, $T K I$ tyrosine kinase inhibitor

a These are selected studies focusing on pivotal trials

b Patients remaining on core study treatment at 5 years

c 268 patients were randomized to each arm; however, 54 failed screening; 3 patients randomly assigned to imatinib arm were not treated

d Patients were resistant or intolerant to imatinib

e $45 \%$ if measured only by metaphase analysis and excluding fluorescence in situ hybridization analysis and also excluding MCyR responders who had an MCyR at baseline or who had a missing cytogenetic analysis at baseline

f $56 \%$ for imatinib-resistant patients and $66 \%$ for imatinib-intolerant patients

9 Molecular response was assessed in 294 of the 321 patients

$\mathrm{h}$ Patients remaining on study at data cutoff were not included in the publication

i 600 patients were assessed for molecular response

j 186 evaluable patients

k 132 evaluable patients

I 80 evaluable patients

${ }^{\mathrm{m}} 68$ evaluable patients 
Table 2 Responses seen in studies of $3 L$ therapy

\begin{tabular}{|c|c|}
\hline 3 L study & Efficacy \\
\hline $\begin{array}{l}\text { A retrospective study of patients receiving } 2 \mathrm{~L} \text { dasatinib or nilotinib after } \\
\text { imatinib [55] }\end{array}$ & $\begin{array}{l}\text { Significant correlation between higher rates of CCyR and DMR and no treat- } \\
\text { ment interruption with } \leq 2 \mathrm{~L} \\
5 \text {-year OS was } 83.0 \% \text { in total and } 94.5 \% \text { in patients with CML-CP }\end{array}$ \\
\hline A report of patients treated with 3 sequential TKIs [27] & $\begin{array}{l}\text { Best response to } 3 \mathrm{~L} \text { 2GTKI in } 48 \text { patients was MMR in } 5 \text { patients, CCyR in } 3 \\
\text { patients, partial or minor CyR in } 5 \text { patients, and CHR in } 6 \text { patients }\end{array}$ \\
\hline $\begin{array}{l}\text { A report of patients treated with dasatinib or nilotinib after failing } \\
\text { imatinib [57] }\end{array}$ & Rates of MCyR, CCyR, and MMR were $50.0 \%, 34.6 \%$, and $19.2 \%$, respectively \\
\hline A study of patients receiving $3 L$ nilotinib or dasatinib [58] & $\begin{array}{l}\text { CHR, MCyR, CyR, CCyR, and MMR rates were } 31.7 \%, 7.3 \%, 14.6 \%, 17.1 \% \text {, and } \\
15.9 \% \text {, respectively, with } 14.6 \% \text { having no response } \\
\text { Overall, } 14 \% \text { of patients died }\end{array}$ \\
\hline A retrospective study of patients on $3 \mathrm{~L}[52]$ & $\begin{array}{l}\text { MCyR and CCyR were achieved in } 15 \text { of } 45 \text { and } 11 \text { of } 52 \text { patients, respec- } \\
\text { tively } \\
\text { Overall, } 13 \text { patients died }\end{array}$ \\
\hline $\begin{array}{l}\text { A single-center study of nilotinib or dasatinib in patients who failed } 2 \\
\text { prior TKIs [59] }\end{array}$ & $\begin{array}{l}\text { CHR, CCyR, and MMR were achieved in } 89 \%, 13 \% \text {, and } 24 \% \text {, respectively, of } \\
\text { patients with CML-CP } \\
\text { Of patients with CHR, } 56 \% \text { lost that response within a median of } 23 \text { months } \\
5 \text {-year OS, PFS, and EFS were } 86 \%, 54 \% \text {, and } 22 \% \text {, respectively }\end{array}$ \\
\hline
\end{tabular}

$2 G T K I$ second-generation tyrosine kinase inhibitor, $2 L$ second line, $3 L$ third line, $C C y R$ complete cytogenetic response, $C H R$ complete hematologic response, $C M L-C P$ chronic myeloid leukemia in chronic phase, CyR cytogenetic response, DMR deep molecular response, EFS event-free survival, MCyR major cytogenetic response, MMR major molecular response, OS overall survival, PFS progression-free survival, TKI tyrosine kinase inhibitor

in patients with progression to $\mathrm{CML}-\mathrm{AP} / \mathrm{BC}$ while receiving TKI therapy, and in those with resistance or intolerance to TKIs $[4,5]$. It may also be used in patients with T315I mutations after an inadequate response to attempted ponatinib therapy [45]. Patients with CMLCP undergoing allo-SCT within the first year of diagnosis have a 5 -year survival rate of $\approx 70 \%$, while those receiving allo-SCT after this time have a 5-year survival rate of $60 \%$ [51]. The 3-year survival rate is $86 \%$ with busulfan plus cyclophosphamide prior to hematopoietic cell transplant, and $\approx 90 \%$ of these patients achieve molecular remission [51]. Potential complications with this treatment include graft-vs-host disease, and outcomes may be influenced by phase of disease, age, and the stem cells used [51].

\section{Therapeutic goals in $3 \mathrm{~L}+$ patients}

ELN 2020 and NCCN have developed recommendations/guidelines for assessment of response in $1 \mathrm{~L}$ and $2 \mathrm{~L}$ treatment, lack guidance for $3 \mathrm{~L}$ therapy and beyond, reflecting the lack of sufficient data in this setting. According to ELN 2020 recommendations, patients are considered to fail $2 \mathrm{~L}$ therapy and recommended to switch to $3 \mathrm{~L}$ therapy if $B C R-A B L 1^{\mathrm{IS}}>10 \%$ is confirmed within 1 to 3 months of therapy, $B C R-A B L 1^{\mathrm{IS}}>10 \%$ by 6 months, $B C R-A B L 1^{\mathrm{IS}}>1 \%$ by 12 months, or $B C R$ $A B L 1^{\mathrm{IS}}>1 \%$ at any time with resistance mutations or other high-risk chromosomal abnormalities in $\mathrm{Ph}+$ cells [5]. Per NCCN guidelines, patients are considered to fail $2 \mathrm{~L}$ therapy and recommended to switch to $3 \mathrm{~L}$ therapy if $B C R-A B L 1^{\mathrm{IS}}>10 \%$ at 6 and 12 months [4]. However, the clinical benefit of switching to $3 \mathrm{~L}$ therapy for patients meeting these definitions has not been demonstrated.

The acceptable response to $3 \mathrm{~L}+$ treatment remains undefined by ELN and NCCN. However, BCR$A B L 1^{\mathrm{IS}}>1 \%$ or lack of a CCyR is considered an insufficient response for optimal survival, predicting a high risk of disease progression in these cases $[4,5]$. Data thus far demonstrate that use of an alternative 2GTKI in patients who experience failure on multiple TKIs is not regularly associated with high rates of response and the responses achieved are not usually durable [4, 27, 52]. Resistance to therapy can be caused by both novel mutations in $B C R$ $A B L 1$ and non-BCR-ABL1-mediated mechanisms [39, $53,54]$.

\section{Clinical trials with a 3L 2GTKI after failure of imatinib and a 2GTKI}

Many reports, mostly case series, of 3L 2GTKIs following failure of imatinib and another 2GTKI have demonstrated poor long-term outcomes (summarized in Table 2).

\section{Bosi et al. [55]}

A retrospective study was conducted to evaluate patient characteristics and outcomes in a cohort of 90 patients with CML without access to new or investigational therapies who received $1 \mathrm{~L}$ imatinib; those experiencing progression were treated with $2 \mathrm{~L}$ or $3 \mathrm{~L}$ dasatinib or nilotinib. Most patients had CML-CP (90\%); 6.7\% had CMLAP; and 3.3\% had CML-BC. Thirty-five patients (38.8\%) were relapsed, refractory, or intolerant to imatinib, and 
13 (14.5\%) needed $\geq 3$ lines of therapy. A significant correlation was found between higher response rates (CCyR and DMR) and no treatment interruption and patients not needing $>2 \mathrm{~L}$ therapy. Five-year OS in the total population was $83 \%$ and was $94.5 \%$ in patients with CML$\mathrm{CP}$ (excluding deaths not related to CML). Five-year OS decreased to $82 \%$ and $77 \%$ in patients receiving $2 \mathrm{~L}$ and $3 \mathrm{~L}+$ therapies, respectively.

\section{Garg et al. [27]}

In this report, a total of 48 patients were treated with 3 sequential TKIs-34 of whom were treated with dasatinib after imatinib and nilotinib and 14 with nilotinib after imatinib and dasatinib. Before the start of $3 \mathrm{~L}$ therapy, 25 patients were in CP. Best response to $3 \mathrm{~L} 2 \mathrm{GTKI}$ was an MMR in 5 patients, a CCyR in 3 patients, a partial and minor CyR in 5 patients, a CHR in 6 patients, and no response in 6 patients, with a median failure-free survival of 20 months. Three patients with CML-CP who achieved a CCyR had responses lasting > 12 months.

\section{Giles et al. [56]}

This analysis assessed the efficacy of nilotinib after failure of $1 \mathrm{~L}$ imatinib and $2 \mathrm{~L}$ dasatinib. Sixty patients with $\mathrm{Ph}+\mathrm{CML}-\mathrm{CP} / \mathrm{AP}$ were enrolled to receive nilotinib $400 \mathrm{mg}$ twice a day (BID). The median duration of followup was 12 months, with $3 \mathrm{~L}$ nilotinib treatment ongoing at the time of the report in 22 patients. The most common reasons for discontinuation in patients with CML-CP included progression (11 patients) and AEs (4 patients). The median duration of nilotinib exposure was 11 months in patients with CML-CP. Of the 37 evaluable patients with CML-CP, 22 of $28(79 \%)$ without a CHR at baseline achieved a CHR, 16 (43\%) achieved an MCyR, and $9(24 \%)$ achieved a CCyR. CHR was maintained until data cutoff, and the duration of MCyR ranged from 3.2 to 23 months. The 4 patients with baseline T315I mutations (including 2 with CML-CP) did not respond to nilotinib therapy.

\section{Ibrahim et al. [57]}

In this cohort of 26 patients with CML-CP, 20 had been treated with dasatinib and 6 with nilotinib after failing imatinib in different phase II trials. Median follow-up after the start of $3 \mathrm{~L}$ therapy was 21.5 months. During follow-up, $42.3 \%$ of patients failed 3L therapy and 34.6\% died. MCyR, CCyR, and MMR rates were $50.0 \%, 34.6 \%$, and $19.2 \%$, respectively. Multivariate analyses showed that a CyR achieved on imatinib or $2 \mathrm{~L}$ therapy was an independent predictor of a CCyR with $3 \mathrm{~L}$ therapy, and achievement of a CyR with $2 \mathrm{~L}$ therapy was the only independent predictor of an MCyR. Patients with a CCyR on 1 of the 2 previous therapies had a significantly higher probability of achieving a CCyR in the $3 \mathrm{~L}$ setting. Achievement of a CCyR on $2 \mathrm{~L}$ therapy and age $<64$ years were independent predictors of OS. All patients with primary cytogenetic resistance to both $1 \mathrm{~L}$ and $2 \mathrm{~L}$ therapies failed to achieve a CCyR on 3L TKI therapy.

\section{Russo Rossi et al. [58]}

This manuscript reports outcomes of $3 \mathrm{~L}$ nilotinib or dasatinib therapy in patients with failure on 2 prior TKIs. A total of 82 patients received 3 sequential TKIs: 34 patients received $3 \mathrm{~L}$ dasatinib, of whom 30 (88.2\%) were in $\mathrm{CP} ; 48$ patients received 3L nilotinib, of whom 38 (79\%) were in CP. Responses to 3L TKI therapy included 13 (15.9\%) patients with an MMR, 14 (17.1\%) with a CCyR, $12(14.6 \%)$ with a PCyR, 6 (7.3\%) with an MCyR, 26 (31.7\%) with only a CHR, and 12 (14.6\%) with no response. Response rates were transient; $30-50 \%$ of patients did not achieve a CCyR within 12 months. In patients receiving $3 \mathrm{~L}$ dasatinib, $41.2 \%$ discontinued due to toxicity and $26 \%$ experienced transformation. In patients receiving $3 \mathrm{~L}$ nilotinib, $50 \%$ discontinued due to toxicity and $21 \%$ experienced transformation. As patients went through more TKIs, an increased frequency of mutations was observed in patients. Overall, $14 \%$ of patients died, and the onset of T315I mutation was associated with an increased risk of death.

\section{Lomaia et al. [52]}

This retrospective study assessed outcomes in 53 patients on 3L therapy; 18 were treated with nilotinib, 33 with dasatinib, and 5 with bosutinib. Forty-eight patients discontinued previous TKI therapy because of resistance, with 42 patients experiencing resistance to both prior TKIs. MCyR and CCyR were achieved in 15 of 45 and 11 of 52 patients with median durations of 9.3 and 4.5 months, respectively. Intolerance was the main reason for treatment discontinuation (5 patients). Progression on or after therapy occurred in 8 patients, with a median time to progression of 14.7 months. Two-year OS was $67 \%$. All patients with an MCyR were alive and maintained CP; however, 13 patients died on study.

\section{Ribeiro et al. [59]}

This single-center study evaluated nilotinib or dasatinib in patients with failure after 2 prior TKIs. The objective was to assess hematologic, cytogenetic, and molecular responses and progression-free survival (PFS), event-free survival (EFS), and OS in patients treated with a third TKI. Of the 25 patients evaluated, 9 were treated with $3 \mathrm{~L}$ dasatinib and 16 with 3L nilotinib. Eighteen patients had CML-CP, of whom $89 \%$ achieved a CHR; $13 \%$ achieved a CCyR, and 24\% achieved an MMR. Fifty-six percent of patients with CML-CP who had a CHR lost that response 
within a median of 23 months. Five-year OS, PFS, and EFS were $86 \%, 54 \%$, and $22 \%$, respectively, in patients with CML-CP, and $66 \%, 66 \%$, and $0 \%$ in patients with CML-AP. All patients with CML-BC died during this study. Responses obtained using a 3L TKI were generally not sustained; however, the authors suggested that this therapy might be useful as a temporizing measure until a donor becomes available for allo-SCT.

\section{Clinical trials with omacetaxine in $3 \mathrm{~L}+$}

Omacetaxine is a semisynthetic formulation of homoharringtonine that induces apoptosis in BCR-ABL1-bearing cells by down-regulating MCL1 and also by inhibiting protein synthesis through binding to ribosomes at their A-cleft [47]. Omacetaxine is approved in the USA for patients with CML-CP resistant or intolerant to $\geq 2$ TKIs, including patients with T315I mutation after TKI failure [49]. Data were pooled from 2 open-label, single-arm, phase II studies [60, 61]. Patients received induction therapy (omacetaxine $1.25 \mathrm{mg} / \mathrm{m}^{2}$ BID subcutaneously for up to 14 consecutive days every 28 days until hematologic response) followed by maintenance therapy (omacetaxine $1.25 \mathrm{mg} / \mathrm{m}^{2}$ BID for up to 7 days per 28-day cycle, for up to 24 months or until progression or toxicity) [50]. A total of 81 patients with CML-CP enrolled in this study [50]. Of 76 evaluable patients, 53 (70\%), 14 (18\%), and 7 (9\%), respectively, achieved a CHR, an MCyR, and a CCyR. Twenty-two patients had T315I mutations at baseline, of whom 18 (82\%), 5 (23\%), and 3 (14\%), respectively, achieved a CHR, an MCyR, and a CCyR. Of 40 patients who received 2 prior TKIs, 31 (78\%), 10 (25\%), and 5 (13\%), respectively, achieved a CHR, an MCyR, and a CCyR; of 36 patients who received 3 prior TKIs, 22 (61\%), $4(11 \%)$, and $2(6 \%)$, respectively, achieved a CHR, an $M C y R$, and a CCyR. The median PFS values for the evaluable population and for patients who received $>3$ cycles of therapy were 9.6 and 9.9 months, respectively. The median OS values for the evaluable population and for those who received $>3$ cycles were 40.3 and 49.3 months, respectively [50].

The most common nonhematologic AEs of any grade were diarrhea (43\%), nausea (38\%), fatigue (30\%), infections $(26 \%)$, pyrexia $(22 \%)$, headache $(22 \%)$, asthenia (22\%), and arthralgia (20\%). Grade 3/4 thrombocytopenia, neutropenia, and anemia occurred in $67 \%, 48 \%$, and $40 \%$ of patients with CML-CP, respectively. Serious AEs occurred in 46 patients (57\%) with CML-CP. The most common any-grade hematologic serious AEs occurring in $\geq 5 \%$ of patients were bone marrow failure (11\%), thrombocytopenia (11\%), and febrile neutropenia (7\%); no nonhematologic serious AEs occurred in $\geq 5 \%$ of patients with CML-CP. Two deaths occurred on study or within the first 30 days of follow-up (due to disease progression and multiorgan failure $[n=1$ each]); none were related to study drug [50].

Long-term administration of omacetaxine was feasible and safe; dose adjustments were frequently required to manage myelosuppression. However, $\mathrm{MCyR}$ and CCyR rates were modest $(<25 \%)$ in all patient cohorts. Patients with $>3$ cycles of omacetaxine treatment showed a trend toward longer PFS and OS compared with the overall population, but only a small number of patients with CML-CP demonstrated durable responses. Overall PFS was $<10$ months, and overall OS was $<4$ years [50]. Because of its modest clinical activity, omacetaxine is mostly used in patients who have used or cannot use any of the available TKIs and are not eligible for allo-SCT.

\section{Prospective clinical trials of TKIs in $3 \mathrm{~L}$ Phase $\mathrm{I} / \mathrm{Il}$ trial to determine efficacy and safety of $3 \mathrm{~L}+$ bosutinib in patients with CML-CP resistant or intolerant to imatinib plus dasatinib and/or nilotinib $[18,62]$}

Adult patients with $\mathrm{Ph}+\mathrm{CML}-\mathrm{CP}$ who received imatinib followed by dasatinib and/or nilotinib were enrolled in this prospective study. The cohort of patients analyzed was either imatinib resistant ( $\geq 600 \mathrm{mg} /$ day) or imatinib intolerant (any dose) and had $\geq 1$ of the following: resistance to dasatinib ( $\geq 100 \mathrm{mg} /$ day), intolerance to any dose of dasatinib, resistance to nilotinib ( $800 \mathrm{mg} /$ day), intolerance to any dose of nilotinib, or resistance/intolerance to dasatinib and nilotinib. Dose escalation to bosutinib $600 \mathrm{mg} /$ day was allowed in patients with no CHR by week 8 or no CCyR by week 12, except in patients with grade $\geq 3$ treatment-emergent AEs (TEAEs).

There were $41(14 \%)$ patients still on bosutinib after $\geq 9$ years of treatment. At $\geq 8$ years of follow-up, the median duration of treatment was 26 months overall and median duration of follow-up was 54 months. Most patients $(90 / 119 ; 76 \%)$ discontinued therapy by 4 years, with a further 21 patients discontinuing therapy since then. Main reasons for discontinuation included AEs (28; $24 \%)$, progressive disease $(24 ; 20 \%)$, or lack of efficacy $(22 ; 18 \%)$. Half the patients received dose reductions because of AEs. The 4-year cumulative confirmed CHR, MCyR, and CCyR rates were $74 \%, 40 \%$, and $32 \%$, respectively. The Kaplan-Meier (KM)-estimated probabilities of maintaining confirmed $\mathrm{CHR}$ and MCyR at 4 years were $63 \%$ and $69 \%$, respectively. The MCyR rate differed among the 3 main subsets of imatinib resistant/intolerant patients: additional dasatinib intolerance, $87 \%$; additional nilotinib resistance, $78 \%$; and additional dasatinib resistance, $43 \%$. At 4 years, cumulative incidence of on-treatment progressive disease or death was $24 \%$ overall, with a total of $26(22 \%)$ on-study deaths. The KM-estimated 4 -year OS was $78 \%$, and 9 -year OS was $74 \%$. A minimal $\mathrm{CyR}$ with prior dasatinib and/or nilotinib predicted 
survival, and a lower $\mathrm{Ph}+$ ratio at baseline $(\leq 35 \%)$ predicted achievement of an MCyR or a CCyR in this study. Most responses were observed within the first year of treatment and discontinuation rates were high, with $68 \%$ of discontinuations (due to AEs) occurring during year 1.

TEAEs were reported in all 119 patients, with grade $3 / 4$ TEAEs being reported in $81(68.1 \%)$ patients. The most common TEAEs included diarrhea (83\%), nausea (48\%), vomiting (38\%), and thrombocytopenia (39\%). Overall, 33 (28\%) patients discontinued treatment because of AEs. Cross-intolerance to bosutinib was reported in 20\% of imatinib-intolerant patients and in $24 \%$ of dasatinibintolerant patients.

\section{Ponatinib efficacy and safety in $\mathrm{Ph}+$ leukemia: final 5-year results of the phase II PACE trial [19]}

Ponatinib is a 3G ATP-competitive TKI with activity against T315I and all other tested BCR-ABL mutations. Adult patients with $\mathrm{CML}$ or $\mathrm{Ph}+$ acute lymphoblastic leukemia (ALL) resistant or intolerant to dasatinib or nilotinib, or patients with CML-CP with T315I mutation regardless of prior TKI therapy, were enrolled in the pivotal PACE trial. Ponatinib was administered at a starting dose of $45 \mathrm{mg}$ once a day (QD). Dose adjustments were allowed to manage AEs; however, because of concerns about arterio-occlusive events (AOEs), dose reductions to 15 and $30 \mathrm{mg}$ QD were recommended in October 2013 (2 years after enrollment ended in October 2011) for all patients with CML-CP with or without an MCyR, respectively.

In the final 5-year follow-up report of PACE, among the cohort of 270 patients with CML-CP, $64(24 \%)$ of whom had the T315I mutation, the median duration of treatment was 32.1 months, with a median follow-up of 56.8 months. Fifty-seven (21\%) patients discontinued because of AEs, 29 (11\%) discontinued because of disease progression, and 15 (6\%) discontinued because of lack of efficacy.

The CyR was evaluable in 267 patients: 159 (60\%) achieved an MCyR at any time, of whom 144 (54\%) achieved a CCyR; 108 (40\%) achieved an MMR; and 64 (24\%) achieved $\mathrm{MR}^{4.5}$. Median times to MCyR, CCyR, and MMR among those who achieved the response were $2.8,2.9$, and 5.5 months, respectively. Of those who achieved an MCyR at 12 months and an MMR at any time, $82 \%$ and $59 \%$ of patients, respectively, maintained responses at 5 years. The KM-estimated PFS and OS at 5 years were $53 \%$ and $73 \%$, respectively.

The most common TEAEs $(\geq 40 \%)$ were rash $(47 \%)$, abdominal pain (46\%), thrombocytopenia (46\%), headache $(43 \%)$, dry skin (42\%), and constipation (41\%). The most common grade $3 / 4$ TEAEs $(\geq 10 \%)$ were thrombocytopenia (35\%), neutropenia (17\%), hypertension
(14\%), increased lipase (13\%), abdominal pain (10\%), and anemia (10\%). AOEs were reported in $84(31 \%)$ patients and were serious in $69(26 \%)$ patients: cardiovascular, cerebrovascular, and peripheral vascular events occurred in $42(16 \%), 35(13 \%)$, and $38(14 \%)$ patients, with serious events in 33 (12\%), 28 (10\%), and 31 (11\%) patients, respectively. Thirty-five (13\%) patients had dose adjustments as a result of AOEs. Five patients had grade 5 AOEs; among patients with CML-CP, these included acute myocardial infarction $(n=1)$, cerebrovascular accident $(n=1)$, and hemorrhagic cerebral infarction $(n=1)$; patients with $\mathrm{Ph}+$ ALL experienced mesenteric arterial occlusion $(n=1)$ and peripheral ischemia $(n=1)$.

Overall, $56 \%$ of patients with CML-CP achieved the primary endpoint of MCyR by 12 months. The cumulative incidence of AOEs continued to increase over time, with events occurring overwhelmingly among patients with additional risk factors for such events. Ponatinib is thus a valuable option for patients who have received prior therapy, but safety considerations have limited its use. An ongoing study (NCT02467270, OPTIC study) is assessing the optimal dose schedule for ponatinib to strike a balance between efficacy and safety [63]. In this study, patients were randomized to receive either ponatinib at $45 \mathrm{mg}$ daily (cohort A), $30 \mathrm{mg}$ daily (cohort B), or $15 \mathrm{mg}$ daily (cohort C). Upon achieving $B C R-A B L 1^{\mathrm{IS}} \leq 1 \%$, the patients receiving $45 \mathrm{mg}$ or $30 \mathrm{mg}$ daily reduced their doses to $15 \mathrm{mg}$ daily. Preliminary analyses show that $39 \%$, $27 \%$, and $26 \%$ of patients in cohorts $\mathrm{A}, \mathrm{B}$, and $\mathrm{C}$, respectively, achieved $B C R-A B L 1^{\mathrm{IS}} \leq 1 \%$ at 12 months. AOEs occurred in $5 \%, 4 \%$, and $1 \%$ of patients in cohorts $\mathrm{A}, \mathrm{B}$, and $\mathrm{C}$, respectively, with serious AOEs reported in $2 \%$, $3 \%$, and $0 \%$, respectively. Discontinuations due to TEAEs occurred in $18 \%, 15 \%$, and $14 \%$ of patients in cohorts A, $\mathrm{B}$, and C, respectively, with 4 (1.4\%) deaths on study [63]. Ponatinib was recently approved for use in patients who have failed $\geq 2$ TKIs, with dose reductions down to $15 \mathrm{mg}$ daily upon achievement of response [38]. Still, other $3 \mathrm{~L}+$ options are needed in patients who fail to achieve responses on ponatinib or who may not be optimal candidates because of the risk of AOEs (Table 3).

\section{Overview of new BCR-ABL1-targeted therapies in development}

New CML therapies are in development, with particular focus on 3L therapy and/or patients with a T315I mutation-settings for which treatment options remain limited and suboptimal. HQP1351 (olverembatinib) is a 3G BCR-ABL1 TKI with in vitro activity against T315I and other mutants, as well as nonmutated BCR-ABL. It has shown a manageable safety profile and significant and lasting efficacy in a phase I study in patients with CML who are resistant to current TKI therapies, particularly 
Table 3 Efficacy and safety results from prospective clinical trials of TKls in the $3 \mathrm{~L}$

\begin{tabular}{|c|c|c|}
\hline Trial & Efficacy & Safety \\
\hline $\begin{array}{l}\text { A phase } I / / I \text { trial of } 3 L+\text { bosutinib in patients } \\
\text { with } C M L-C P \text { resistant/intolerant to } \\
\text { imatinib + dasatinib and/or nilotinib } \\
\text { (Study 200) [18] }\end{array}$ & $\begin{array}{l}\text { At } 4 \text { years: } \\
74 \% \text { cumulative CCHR } \\
63 \% \text { probability of maintaining CCHR } \\
40 \% \text { cumulative MCyR } \\
69 \% \text { probability of maintaining MCyR } \\
24 \% \text { cumulative incidence of on-treatment } \\
\text { CML-AP/BC or death and 22\% on-study deaths } \\
78 \% \text { KM-estimated OS }\end{array}$ & $\begin{array}{l}\text { TEAEs reported in } 100 \% \text { of patients and grade } 3 / 4 \\
\text { TEAEs reported in } 68.1 \% \text { of patients } \\
\text { Most common TEAEs were diarrhea ( } 83 \%) \text {, nausea } \\
(48 \%) \text {, vomiting (38\%), and thrombocytopenia } \\
(39 \%)\end{array}$ \\
\hline $\begin{array}{l}\text { Ponatinib efficacy and safety in } \mathrm{Ph}+\text { leukemia } \\
{[19,46]}\end{array}$ & $\begin{array}{l}\text { Overall, in patients with CML-CP [19]: } \\
60 \% \text { achieved MCyR at any time, of whom 54\% } \\
\text { achieved CCyR } \\
40 \% \text { achieved MMR } \\
24 \% \text { achieved MR.5 } \\
3 \% \text { of patients transformed to CML-AP/BC } \\
\text { KM-estimated PFS and OS at } 5 \text { years was 53\% } \\
\text { and } 73 \% \text {, respectively } \\
\text { In a study of patients with CML-CP and resist- } \\
\text { ance/intolerance to nilotinib or dasatinib or } \\
\text { who had a T315I mutation [46]: } \\
51 \% \text { of patients with intolerance/resistance and } \\
70 \% \text { with T315I mutation achieved MCyR, with } \\
40 \% \text { and } 66 \% \text { achieving CCyR, respectively } \\
\text { MMR was achieved in } 27 \% \text { of patients with } \\
\text { resistance/intolerance to nilotinib or dasatinib } \\
\text { and } 56 \% \text { of patients with a T315I mutation } \\
12 \% \text { of patients discontinue use due to AEs }\end{array}$ & 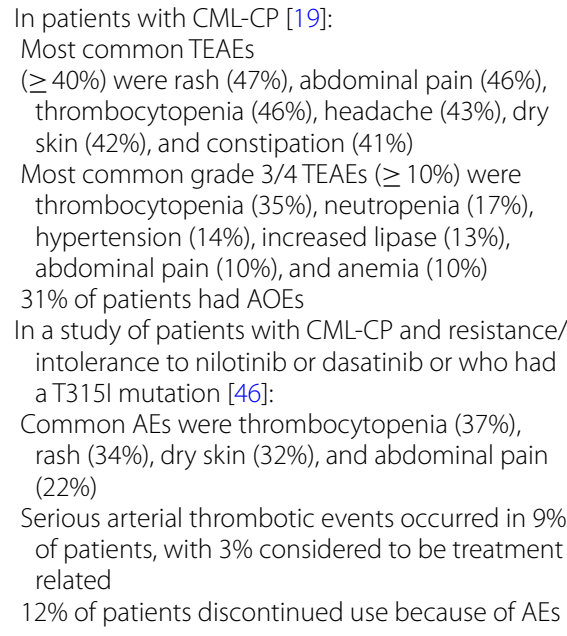 \\
\hline
\end{tabular}

$3 L$ third line, $A E$ adverse event, $A O E$ arterio-occlusive event, $C C H R$ cumulative confirmed complete hematologic response, $C C y R$ complete cytogenetic response, $C M L-A P$ chronic myeloid leukemia in acute phase, $C M L-B C$ chronic myeloid leukemia in blast crisis, CML-CP chronic myeloid leukemia in chronic phase, $K M$ KaplanMeier, $M C y R$ major cytogenetic response, $M M R$ major molecular response, $M R^{4.5} 4.5$-log molecular response $\left(B C R-A B L 1^{15} \leq 0.0032 \%\right)$, $O S$ overall survival, $P h+$ Philadelphia chromosome positive, PFS progression-free survival, TEAE treatment-emergent adverse event, TKI tyrosine kinase inhibitor

among those with T315I mutations [64-67]. Unlike other TKIs, HQP1351 does not form a hydrogen bond with the hydroxyl group of the BCR-ABL T315 residue, allowing it to bind in the presence of T315I mutations [66]. HQP1351 was orally administered (1-60 mg) every other day. The median duration of follow-up was 12.8 months. Among evaluable patients with CML-CP, 52 of 55 (94.5\%) without a CHR at baseline achieved a CHR; 56 of 81 (81\%) without a CCyR at baseline achieved an MCyR and 49 (60.5\%) achieved a CCyR; and 32 of 86 (37.2\%) without an MMR at baseline achieved an MMR. More patients with CML-CP harboring the T315I mutation achieved a $\mathrm{CHR}$, an MCyR, a CCyR, and an MMR than those without the mutation [64]. Thrombocytopenia was the most common hematologic TEAE reported in patients, with any-grade and grade $3 / 4$ thrombocytopenia reported in $75.2 \%$ and $49.5 \%$ of patients, respectively [64]. Preliminary results from a two-part phase II HQP1351 trial in heavily pretreated patients with CML-CP (study CC201) and CML-AP (study CC202) harboring the T315I mutation were recently published [68]. Patients in both studies were treated with HQP1351 $40 \mathrm{mg}$ once every other day for 28 consecutive days per cycle over 24 months. For study CC201, 41 patients enrolled in the trial and
92.7\% completed at least 6 cycles of therapy. The 3- and 6-month PFS was $100 \%$ and $96.7 \%$ across the median duration of follow-up of 7.9 months. Among 31 evaluable patients without CHR at baseline, $30(96.8 \%)$ achieved CHR. Among 41 evaluable patients without $\mathrm{CCyR}$ at baseline, 31 (75.6\%) achieved MCyR (the primary objective of the study), including 27 (65.9\%) and 4 (9.85) who achieved CCyR and PCyR, respectively. Of 41 evaluable patients, $20(48.8 \%)$ achieved MMR. Frequent grade $\geq 3$ treatment-related AEs were thrombocytopenia (48.8\%), anemia (24.4\%), neutropenia (19.5\%), and leukopenia (12.2\%). Frequent nonhematologic treatment-related all-grade AEs were skin pigmentation (53.7\%) and elevated creatine kinase $(48.8 \%)$, alanine aminotransferase (31.7\%), and aspartate aminotransferase (26.8\%) [68]. For study CC202, 23 patients enrolled in the trial and 78.3\% completed at least 6 cycles of therapy. Across the median duration of follow-up of 8.2 months, the 3-and 6-month PFS was $100 \%$ and $95.5 \%$. At baseline, 23 patients did not have a major hematologic response; 18 (78.3\%) of patients achieved this response on study (the primary endpoint of this study). Of the 23 evaluable patients without MCyR at baseline, 14 (60.9\%) achieved CHR, 12 (52.2\%) achieved MCyR, and 6 (26.1\%) achieved MMR. 
Common grade $\geq 3$ treatment-related AEs were thrombocytopenia (52.2\%), anemia (39.1\%), leukopenia (30.4\%), and neutropenia (21.7\%). The most commonly reported nonhematologic treatment-related all-grade AEs were skin pigmentation (69.6\%), hypocalcemia (52.2\%), proteinuria $(52.2 \%)$, hypertriglyceridemia $(47.8 \%)$, hyperphosphatemia (43.5\%), arthralgia (34.8\%), and fatigue (26.1\%) [68].

PF-114 is another orally available ATP-competitive TKI with efficacy at nanomolar concentrations against both wild-type and mutated BCR-ABL1, including the T315I mutation [69-71]. It is structurally similar to ponatinib but modified to avoid inhibition of vascular endothelial growth factor receptor in an attempt to minimize cardiovascular toxicity. A phase I/II dose-finding study in patients with $\mathrm{Ph}+\mathrm{CML}-\mathrm{CP}$ or CML-AP resistant to $\geq 2$ TKIs and in patients harboring the T315I mutation enrolled 51 patients who received daily doses ranging from 50 to $750 \mathrm{mg}$ [69-72]. At a follow-up of $\geq 6$ months, therapy was ongoing in 17 patients. In the optimal safety and efficacy dose cohort (300 mg QD), 6 of 11 patients achieved an MCyR and 4 patients achieved an MMR. Of 12 patients with T315I mutations, 3 and 4 patients, respectively, achieved a $\mathrm{CHR}$ and an MCyR. Drug-related grade 3 skin toxicity, mostly in the form of psoriasiform lesions, was reported in 11 patients receiving $\geq 400 \mathrm{mg}$ [70].

Vodobatinib (K0706) is another orally bioavailable BCR-ABL1 TKI designed using a structure-guided drugdesign platform with significant activity in vitro against most BCR-ABL mutations, but not T315I [73]. Vodobatinib showed an acceptable safety profile in a phase I study in patients with CML who experienced treatment failure with $\geq 3$ TKIs and/or patients with comorbidities that restrict the use of certain TKIs (nilotinib, dasatinib, and ponatinib) [74, 75]. At the time of data cutoff, 35 patients received doses ranging from 12 to $240 \mathrm{mg}-27$ of whom had CML-CP. Seven and 4 patients with CML$\mathrm{CP}$, respectively, achieved and maintained a CCyR; 5 achieved an MMR; and 2 achieved $\mathrm{MR}^{4.5}$. Of the 12 of 27 responders, 11 remained on treatment with a durable MCyR for 6.9 months; 1 had progression at 9.5 months. Mild to moderate gastrointestinal AEs were reported in $18.5 \%$ of patients. Two patients enrolled had T315I mutations; these patients experienced disease progression in cycle 1 of treatment, leading to a protocol amendment to exclude patients with T315I mutations from this study [74]. In a recently published exploratory analysis, efficacy, and safety of vodobatinib was assessed in ponatinib-pretreated and -naive patients with CML-CP, with the goal of determining MTD or RP2D. Patients received escalating doses of vodobatinib (12 to $240 \mathrm{mg}$ once daily) in 28-day cycles. Sixteen and 15 patients, respectively, enrolled in the ponatinib-pretreated and -naive cohorts. The median duration of treatment was 17.3 months and 14.8 months, respectively. Efficacy was comparable between the 2 cohorts with $50 \%$ ponatinib-pretreated and $67 \%$ naive patients having CCyR. Most common treatment-emergent all-grade AEs were myalgia (33\%), back pain (27\%), thrombocytopenia (27\%), and nasopharyngitis (20\%); 3 CVEs unrelated to study treatment were reported in 2 patients ( 1 in each cohort); 1 ponatinib-pretreated patient died on study due to disease progression and 2 naive patients due to pneumonia and intracranial hemorrhage ( $n=1$ each) [76].

Asciminib is a first-in-class BCR-ABL1 inhibitor Specifically Targeting the ABL Myristoyl Pocket (STAMP inhibitor) [77, 78]. Unlike TKIs that target the ATP binding site, asciminib has a unique mechanism of action, binding to the myristoyl pocket of ABL1 and inhibiting the fusion protein in a non-ATP-competitive manner (Fig. 1). Normally, a myristoyl group will bind the myristate pocket of ABL1, inducing an inactive state and regulating kinase activity; however, this mechanism of autoregulation is lost upon fusion with BCR. Because of its different mechanism of action compared with currently available TKIs, it has a nonoverlapping mutation-driven resistance profile with approved TKIs and maintains activity against BCRABL1 with ATP-site resistance mutations, including the T315I mutation $[79,80]$. Preclinical data has shown that asciminib specifically inhibits the growth of BCRABL1-driven cancer cells, unlike TKIs, which are nonspecific inhibitors of BCR-ABL1. Because of its unique mechanism of action and specificity, asciminib monotherapy was predicted to provide improved efficacy compared with ATP-competitive TKIs in patients with resistance/intolerance to multiple prior TKIs, with a decreased risk of off-target effects [79-81]. The efficacy and safety of asciminib is being assessed in phase I, II, and III clinical trials [82-86].

Because asciminib targets the myristoyl pocket of ABL1, it can bind in combination with ATP-competitive TKIs $[79,80]$. Preclinical studies showed that asciminib in combination with nilotinib (an ATP-competitive TKI) led to complete tumor regression in mice; when used separately, it led to the emergence of resistance mutations [80]. The complementary resistance profiles of asciminib and imatinib, dasatinib, or nilotinib had an additive effect in vitro, similar to that seen with asciminib in combination with ponatinib $[42,80]$. The combination of asciminib and ponatinib at clinically relevant concentrations was effective against compound mutations, including T315I-inclusive compound mutations, and reduced ponatinib-associated toxicities (Table 4) [42]. 


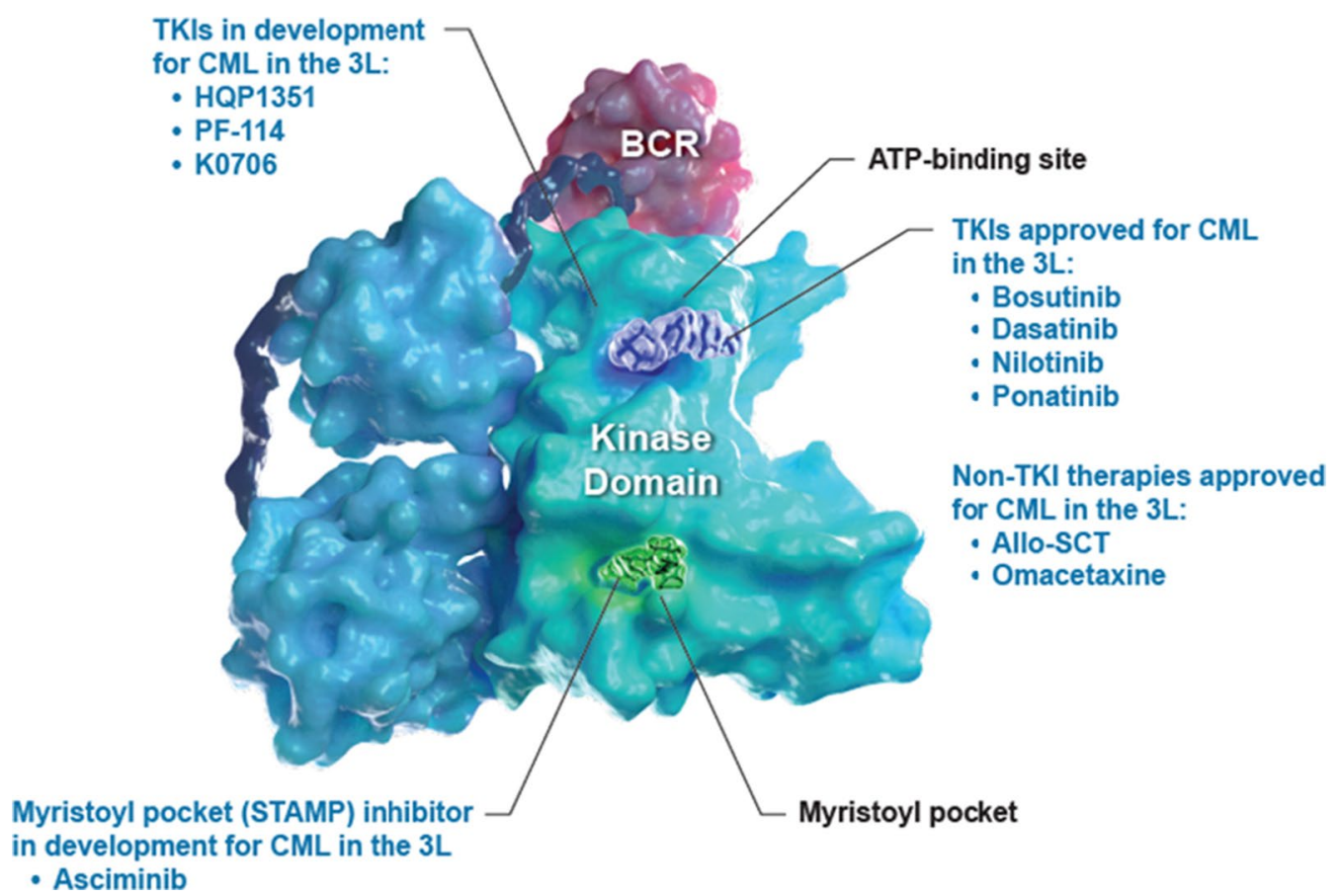

Fig. 1 Therapies in development vs approved therapies for CML in the $3 L+$ setting. $3 L$ third line, allo-SCT allogeneic stem cell transplant, ATP adenosine triphosphate, CML chronic myeloid leukemia, STAMP Specifically Targeting the ABL Myristoyl Pocket, TKI tyrosine kinase

Combinations of asciminib and ATP-competitive TKIs are being investigated in various clinical studies [86-89].

\section{Asciminib in the $3 \mathrm{~L}+$ setting}

A phase I, dose-finding study (NCT02081378) of asciminib alone or in combination with imatinib, nilotinib, or dasatinib enrolled patients aged $\geq 18$ years with $\mathrm{Ph}+\mathrm{CML}-\mathrm{CP}$ or CML-AP who relapsed or were refractory to $\geq 2$ different TKIs or had unacceptable AEs from TKIs. Patients with the T315I mutation were enrolled if they had received $\geq 1$ TKI and if no other treatment was available. Notably, in the expansion cohorts, the dose used for patients with a T315I mutation was considerably higher than that for other patients, based on preclinical data suggesting that higher concentrations are required. The doses used were within the range found safe in the phase I portion of the study. The study is ongoing, but results from the monotherapy cohort have been published [81], and preliminary results from the combination cohorts have also been reported $[90,91]$.

In the monotherapy cohort, 141 patients with CML-CP and 9 patients with CML-AP were enrolled and received asciminib QD or BID (10-200 mg). A maximum tolerated dose was not identified, but the recommended dose for expansion was determined to be $40 \mathrm{mg}$ BID for patients without and $200 \mathrm{mg}$ BID for those with the T315I mutation. Efficacy results were analyzed by T315I status and
CML phase, and safety results were analyzed for the combined cohort of 150 patients [81]. The 5 most common all-grade TEAEs were fatigue (29.3\%), headache $(28.0 \%)$, increased lipase levels (26.7\%), arthralgia (24.0\%), and nausea $(24.0 \%)$ [81].

In patients without the T315I mutation, $92 \%$ of patients without a CHR at baseline achieved a CHR; $60 \%$ of patients achieved an MCyR; $54 \%$ of patients without a CCyR at baseline achieved a CCyR; and 24\% and 36\% of evaluable patients achieved an MMR by 6 and 12 months, respectively, including $23 \%$ and $40 \%$ of patients, respectively, who were resistant or intolerant to ponatinib (Table 5) [81].

In patients with the T315I mutation, $88 \%$ of patients without a CHR at baseline achieved a CHR; 55\% of patients without an MCyR at baseline achieved an MCyR; $41 \%$ of patients without a CCyR at baseline achieved a CCyR; and $21 \%$ and $24 \%$ of evaluable patients achieved an MMR by 6 and 12 months, respectively, including in $14 \%$ and $17 \%$, respectively, of patients who were resistant or intolerant to ponatinib (Table 5) [81]. Although MMR responses are higher among patients who had not previously received ponatinib ( $57.1 \%$ by 24 weeks), patients who had previously received ponatinib still had a $28.6 \%$ MMR rate by 24 weeks [92]. 
Table 4 Ongoing clinical trials for BCR-ABL1-targeted therapies for CML in $3 L+$ setting

\begin{tabular}{|c|c|c|c|}
\hline Drug/trial & Trial number/phase & Goals & Primary endpoint(s) \\
\hline \multirow[t]{2}{*}{ HQP1351 (BCR-ABL1 Inhibitor) $[132,133]$} & NCT04126681/phase II & $\begin{array}{l}\text { To evaluate the efficacy of HQP1351 in patients with } \\
\text { CML-CP who are resistant and/or intolerant to } 1 \mathrm{G} \text { and } \\
\text { 2GTKIs }\end{array}$ & EFS \\
\hline & NCT03883087/phase ॥ & $\begin{array}{l}\text { To evaluate the efficacy of HQP1351 in patients with } \\
\text { CML-CP and a T315I mutation }\end{array}$ & MCyR \\
\hline PF-114 (BCR-ABL1 Inhibitor) [72] & NCT02885766/phase I/II & $\begin{array}{l}\text { To evaluate tolerability, safety, pharmacokinetics, and pre- } \\
\text { liminary efficacy of PF-114 in patients with Ph }+ \text { CML } \\
\text { who are resistant to } 2 \text { GTKIs or have the T315I mutation }\end{array}$ & $\begin{array}{l}\text { DLTS } \\
\text { MTD }\end{array}$ \\
\hline K0706 (BCR-ABL1 Inhibitor) [75] & NCT02629692/phase I/II & $\begin{array}{l}\text { To determine safety, tolerability, pharmacokinetics, and } \\
\text { activity of K0706 in patients with CML or Ph + ALL }\end{array}$ & $\begin{array}{l}\text { MTD } \\
\text { TEAEs } \\
\text { MCyR or partial } \\
\quad \text { cytogenetic } \\
\text { response (CML-CP) } \\
\text { CHR (CML-AP/BC) }\end{array}$ \\
\hline \multirow[t]{2}{*}{ Asciminib (STAMP inhibitor) $[82,86]$} & NCT03106779/phase III & $\begin{array}{l}\text { To compare the efficacy of asciminib with that of bosuti- } \\
\text { nib in patients with CML-CP in the } 3 L+\text { setting }\end{array}$ & MMR at 24 weeks \\
\hline & NCT02081378/phase I & $\begin{array}{l}\text { A dose-finding study of asciminib alone or in combina- } \\
\text { tion with nilotinib, imatinib, or dasatinib in patients } \\
\text { with CML and Ph }+ \text { ALL who are relapsed/refractory to } \\
\text { or are intolerant of TKIs }\end{array}$ & $\begin{array}{l}\text { MTD and/or RDE } \\
\text { DLTs }\end{array}$ \\
\hline
\end{tabular}

$1 G$ first generation, 2GTKI second-generation tyrosine kinase inhibitor, $3 L$ third line, $A L L$ acute lymphoid leukemia, $C H R$ complete hematologic response, $C M L-A P$ chronic myeloid leukemia in acute phase, $C M L-B C$ chronic myeloid leukemia in blast crisis, $C M L-C P$ chronic myeloid leukemia in chronic phase, $D L T$ dose-limiting toxicity, EFS event-free survival, $M C y R$ major cytogenetic response, $M M R$ major molecular response, $M T D$ maximum tolerated dose, Ph+ Philadelphia chromosome positive, RDE recommended dose for expansion, STAMP Specifically Targeting the ABL Myristoyl Pocket, TEAE treatment-emergent adverse event, TKI tyrosine kinase inhibitor

Table 5 Efficacy and safety results from the asciminib monotherapy cohorts of the phase I dose-finding study

\begin{tabular}{|c|c|c|}
\hline Cohort & Efficacy & Safety \\
\hline Cohort without T315I mutations [81] & $\begin{array}{l}37 \%(37 / 99) \text { and } 48 \% \text { (44/91) of all evaluable } \\
\text { patients achieved or maintained MMR by } 6 \text { and } \\
12 \text { months, respectively } \\
77 \%(85 / 110) \text { and } 70 \%(77 / 110) \text { of all evaluable } \\
\text { patients achieved or maintained MCyR and CCyR, } \\
\text { respectively }\end{array}$ & $\begin{array}{l}\text { Study drug-related AEs of any grade were reported } \\
\text { in 100\% (150/150) of patients, and grade } 3 / 4 \text { AEs } \\
\text { were reported in } 60 \%(90 / 150) \text { of patients } \\
\text { The most common AEs of any grade were fatigue } \\
\text { (29.3\%), headache (28.0\%), and increased lipase } \\
(26.7 \%)\end{array}$ \\
\hline Cohort with T315I mutations [81] & $\begin{array}{l}21 \%(4 / 19) \text { and } 24 \%(4 / 17) \text { of all evaluable patients } \\
\text { achieved MMR by } 6 \text { and } 12 \text { months, respectively } \\
55 \%(11 / 20) \text { and } 41 \%(9 / 22) \text { of all evaluable patients } \\
\text { achieved MCyR and CCyR, respectively }\end{array}$ & \\
\hline Cohort with baseline BCR-ABL1 ${ }^{15} \leq 1 \%[77]$ & $\begin{array}{l}\text { 87.5\% of patients remained on therapy at data } \\
\text { cutoff } \\
75 \%(18 / 24) \text { of these patients were in MMR at data } \\
\text { cutoff } \\
\mathrm{MR}^{4} \text { and } \mathrm{MR}^{4.5} \text { were achieved by }>40 \% \text { of evaluable } \\
\text { patients who were not in } \mathrm{MR}^{4} \text { or } \mathrm{MR}^{4.5} \text { at baseline } \\
12.5 \% \text { discontinued due to AEs }\end{array}$ & $\begin{array}{l}\text { Grade } 3 / 4 \text { AEs (in }>10 \% \text { of patients), regardless of } \\
\text { study drug, were increased lipase }(27.1 \%) \text { and } \\
\text { hypertension }(12.5 \%)\end{array}$ \\
\hline
\end{tabular}

$A E$ adverse event, $C C y R$ complete cytogenetic response, $M C y R$ major cytogenetic response, $M M R$ major molecular response, $M R^{4} 4.0$-log molecular response ( $B C R$ $\left.A B L 1^{15} \leq 0.01 \%\right), M R^{4.5} 4.5-\log$ molecular response $\left(B C R-A B L 1^{15} \leq 0.0032 \%\right)$

In a subanalysis of the ongoing phase I study, the safety and efficacy of asciminib monotherapy was evaluated in a subset of patients enrolled in the monotherapy cohort with baseline $B C R-A B L 1^{\mathrm{IS}} \leq 1 \%$-a population considered to be primarily intolerant of TKIs. Asciminib monotherapy was well tolerated, with only $6.2 \%$ of patients discontinuing treatment because of AEs; at data cutoff, the median duration of drug exposure was 161 weeks.
Asciminib was effective in this population as well, with $75 \%, 42 \%$, and $43 \%$ of patients achieving an MMR, $\mathrm{MR}^{4}$, and $\mathrm{MR}^{4.5}$ overall by data cutoff of August 30, 2019, respectively-all of whom did not have those responses at baseline (Table 5). These results set the stage for an ongoing study exploring the use of asciminib in patients who do not achieve optimal outcomes with TKI therapies and miss therapeutic milestones [77]. 
The most frequent all-grade AEs ( $>25 \%$ of patients), regardless of study drug relationship, were fatigue (43.8\%), increased lipase (39.6\%), headache (35.4\%), increased amylase (29.2\%), arthralgia (29.2\%), diarrhea (29.2\%), and abdominal pain (27.1\%) [77]. The most frequent grade $3 / 4$ AEs ( $>5 \%$ of patients), regardless of study drug, were increased lipase (27.1\%) and abdominal pain (12.5\%) [77].

An ongoing phase III, multicenter, randomized study (ASCEMBL) is investigating the efficacy and safety of asciminib $40 \mathrm{mg}$ BID vs bosutinib $500 \mathrm{mg}$ QD in patients with CML-CP previously treated with $\geq 2$ TKIs, with failure of or intolerance to the most recent TKI (NCT03106779) [82]. The goal of this study is to compare the efficacy of asciminib with that of bosutinib in the $3 \mathrm{~L}+$ setting, with the rate of MMR at 24 weeks as the primary endpoint [82]. The primary efficacy and safety results from ASCEMBL (per May 25, 2020, data cutoff) have been reported: 233 patients with CML-CP were randomized in 2:1 ratio to asciminib $40 \mathrm{mg}$ twice daily $(n=157)$ or bosutinib $500 \mathrm{mg}$ once daily $(n=76)$, with a median duration of follow-up of 14.9 months from randomization to cutoff [93].

The study met its primary objective, with an MMR rate of $25.5 \%$ with asciminib and $13.2 \%$ with bosutinib at 24 weeks, and the treatment difference between the 2 treatment arms, after adjusting for the baseline stratification factor (MCyR status), was 12.2\% (95\% CI, 2.19-22.3: 2 -sided $P=0.029$ ). A homogenous and consistent superior treatment effect was observed with asciminib across most major demographic and prognostic subgroups, including in patients who received $\geq 3$ prior TKIS, in those who discontinued their prior TKI due to treatment failure, and regardless of baseline MCyR status [93].

Asciminib had a better safety profile than bosutinib. Grade $\geq 3$ AEs regardless of study drug relationship occurred in $50.6 \%$ of patients on asciminib compared to $60.5 \%$ on bosutinib. The most common grade $\geq 3$ AEs occurring in $>10 \%$ of patients were thrombocytopenia $(17.3 \%)$ and neutropenia (14.7\%) with asciminib and neutropenia (11.8\%), diarrhea (10.5\%), and increased alanine aminotransferase (14.5\%) with bosutinib. Two fatal events occurred on-treatment in the asciminib arm due to ischemic stroke and arterial embolism $(n=1$ each) and 1 in the bosutinib arm due to septic shock [93].

\section{Novel therapies with non-BCR-ABL1 targets in CML}

Key goals in the development of novel therapeutics include addressing non-BCR-ABL1-mediated CML leukemia stem cell (LSC) resistance and inhibiting other molecular pathways upregulated by or co-existing with active BCR-ABL1 signaling via the combination of TKIs with other agents [94-98]. CML LSCs are not eliminated by TKIs as they are not dependent on the kinase activity of BCR-ABL1 for their survival [99-101]. They have thus been suggested to play an important role in drug resistance and persistence, and to interact with the bone marrow microenvironment to evade drugs and host control mechanisms. These cells are thought to be one of the main causes for relapse, nonresponse, and resistance to TKI therapy and of relapse after treatment discontinuation as most TKIs in vitro are unable to eradicate these cells. Some of the novel therapies discussed here have not been effective, and/or clinical development of these therapies has been paused; others have shown preliminary efficacy in patients with CML, including some combinations of TKIs with other agents.

\section{TKIs in combination with other drugs}

Currently approved TKIs combined with various anticancer agents (interferon- $a$, chemotherapeutic agents, immunomodulators) may provide an additive or synergistic effect. Hence, several ongoing clinical trials are investigating the efficacy of approved TKIs with other agents [102]. Interferon-a directly inhibits the proliferation of CML progenitor cells; the pegylated form is being studied in combination with bosutinib [103].

Expression of the immune checkpoint protein programmed cell death 1 ligand 1 (PD-L1) has been observed in patients with CML, particularly in patients classified as high risk by Sokal score [104]. Accordingly, expression of programmed cell death 1 protein (PD-1), the tandem immune checkpoint receptor for PD-L1, is also higher in the $\mathrm{T}$ cells of patients with CML [104]. These data suggest that targeting the PD-1/PD-L1 pathway may be an effective strategy for eliminating CML cells. Several clinical trials investigating immune checkpoint inhibitor therapy in combination with existing TKI therapies are ongoing. In a phase Ib trial investigating the PD-1 inhibitor nivolumab ( 1 or $3 \mathrm{mg} / \mathrm{kg}$ every 2 weeks) in combination with dasatinib, none of the 31 patients enrolled experienced a dose-limiting toxicity (NCT02011945, Study Results) [105]. Among patients with CML-CP with prior dasatinib exposure, 2 of 8 in the $1-\mathrm{mg} / \mathrm{kg}$ group achieved an MMR at 36 months, and 5 of 11 in the 3-mg/ $\mathrm{kg}$ group achieved an MMR at 36 months [105]. In a separate phase I/II trial, several 2GTKIs in combination with the PD-L1 inhibitor avelumab are being investigated in patients with CML-CP [106].

Thiazolidinediones are peroxisome proliferator-activated receptor $\gamma$ agonists that downregulate proteins overexpressed in LSCs. Results from a preclinical study showed that the peroxisome proliferator-activated receptor $\gamma$ agonist pioglitazone sensitized CML cells to imatinib [102, 107]. An ongoing phase I/II study 
is investigating the combination of pioglitazone with imatinib [106].

A subset of $\mathrm{CML}$ cells $(\mathrm{Ph}+\mathrm{CD} 34+)$ aberrantly express dipeptidylpeptidase IV-a protease that deregulates interactions between LSCs and the hematopoietic niche. Dipeptidylpeptidase IV inhibitors or gliptins can restore normal interactions between LSCs and the niche $[102,108]$. Vildagliptin is being investigated in a phase I/ II study in combination with nilotinib as a pretreatment in patients attempting TFR [109]. Other agents in clinical development or with preclinical activity in CML have been considered for the treatment of patients with CML in various settings. Listed below are some such agents; this list is not meant to be comprehensive or all-inclusive, because other agents in early development may also hold promise in various CML settings.

\section{JAK/STAT inhibitors}

JAK activation leads to increased STAT phosphorylation, nuclear translocation, and transcriptional activity; activation of this pathway is observed in CML [110]. Preclinical studies have demonstrated that the JAK2 inhibitor ruxolitinib results in a reduction of quiescent $\mathrm{CML}$ LSCs [110]. In a phase I trial of ruxolitinib in combination with nilotinib in patients with CML-CP, a reduction in phosphorylated-STAT3 was observed after treatment, and $10(40 \%)$ patients had undetectable $B C R-A B L 1$ transcripts [111]. The safety and efficacy of adding ruxolitinib to established therapy with bosutinib, nilotinib, or dasatinib is currently being studied in a phase II trial (NCT03654768) [112].

\section{Wnt/ $\beta$-catenin inhibitors}

Wnt/ $\beta$-catenin pathway inhibitors may be effective for CML, because $\beta$-catenin-the canonical Wnt pathway's central effector-is required for the development and maintenance of LSCs [113]. Preclinical studies have shown that combination of the $\mathrm{Wnt} / \beta$-catenin inhibitor PRI-724 with nilotinib reduced the viability of quiescent CML cells in vitro and extended the survival of mice transplanted with TKI-resistant CML cells [113]. A phase I study was completed, but further clinical development is not ongoing [114].

\section{Liposome-incorporated antisense oligodeoxynucleotide}

BP1001 is a liposome-incorporated antisense oligodeoxynucleotide that stops expression of growth factor receptor-bound protein 2 (Grb2) - a signal transducer. Grb2 mediates the activation of the oncogenic tyrosine kinases MAPK1 and MAPK3. As a single agent, BP1001 induced responses in a handful of patients with CML with resistance to multiple prior therapies [115]. BP1001 demonstrated efficacy and safety in combination with low-dose cytarabine in a phase I trial that enrolled patients with $\mathrm{Ph}+\mathrm{CML}-\mathrm{CP},-\mathrm{AP}$, or - $\mathrm{BC}$ and other hematologic malignancies. BP1001 was administered intravenously, twice weekly for 28 days at a starting dose of $5 \mathrm{mg} / \mathrm{m}^{2}$ with dose escalations ranging from 10 to $90 \mathrm{mg} / \mathrm{m}^{2}$. Of 7 patients who received BP1001 plus cytarabine, 2 had complete remission, 1 had complete remission with incomplete hematologic recovery, and 2 had stable disease with no dose-limiting toxicities. The most common grade $3 / 4$ AEs included cardiopulmonary disorders (64\%) and fever (including neutropenic fever) and infections (44\%) [115].

\section{TGF- $\beta-F O X O-B C L-6$}

The TGF- $\beta$-FOXO-BCL- 6 pathway is involved in the maintenance of LSCs; preclinical data show that treatment of mice with the TGF- $\beta$ inhibitor LY364947 reduced LSC clonogenic activity in vitro [116].

\section{RAS inhibitors}

Addition of a farnesyl moiety to RAS is a key post-translational step toward RAS activation, subsequently activating ERK signaling, which is observed with BCR-ABL1 activation. Inhibiting farnesyl transferase blocks RAS and downstream signaling [117]. Three farnesyl transferase inhibitors have been tested in CML: 2 in phase I clinical trials (tipifarnib and lonafarnib) $[118,119]$ and 1 (BMS214662) in preclinical settings [120]. With tipifarnib, hematologic responses were attained in 17 (68\%) of 25 assessable patients; 9 patients (36\%) also achieved a CyR [118]. Lonafarnib use resulted in 3 patients (33\%) with CML-CP achieving CHR [119]. BMS-214662 potently induced apoptosis of both proliferating and quiescent CML stem/progenitor cells with $<1 \%$ recovery of longterm culture-initiating cells [120]. Despite these findings, clinical development in CML of this class has been paused.

\section{Mechanistic target of rapamycin inhibitors}

Constitutively active mechanistic target of rapamycin signaling is observed in CML and results in excessive cell proliferation and may contribute to resistance to chemotherapy [121]. Rapamycin (sirolimus) and RAD001 (everolimus) have been evaluated in phase I/ II clinical trials; however, the trial evaluating rapamycin (NCT00776373) has been terminated, and 2 trials evaluating RAD001 have been completed without further clinical development [98].

\section{Histone deacetylase inhibitors}

Histone deacetylase inhibitors have been studied in CML: preclinical studies have found that panobinostat in combination with imatinib was able to kill CML progenitor cells that were resistant to imatinib alone and could 
prevent tumor formation when injected into immunodeficient mice [122]. Other histone deacetylase inhibitors (pacrinostat, vorinostat) have demonstrated antileukemic activity [98]. A phase II study evaluated panobinostat monotherapy in patients with CML-CP with resistance to $\geq 2$ TKIs [123]. One of 29 (3\%) patients had a CHR, and 0 patients had an MCyR. Histone deacetylase inhibitors have questionable efficacy in monotherapy and may be best paired with TKIs.

\section{Hypomethylating agents}

Hypomethylating agents are currently being investigated for use in CML in combination with TKIs, because hypermethylation of key genes-including BCR and $\mathrm{ABL}-$ has been reported in CML [124]. A study of decitabine in combination with dasatinib reported a major hematologic response, an MCyR, and an MMR in 48\%, $44 \%$, and $33 \%$, respectively, of patients with CML-CP receiving the combination [125]. Another study assessed azacytidine in combination with TKIs in patients with CML who had a CCyR and minimal residual disease. Only 3 patients enrolled; however, they were able to achieve sustainable $\mathrm{MR}^{4.5}$ after azacytidine was added to their treatment regimens [124].

\section{Aurora kinase pathway inhibitors}

The aurora kinase family regulates cell division, and dysregulation of their activity generates chromosomal abnormalities driving DNA alterations responsible for cell transformation; aurora kinase inhibitors are considered potential anticancer treatments $[96,98]$. A phase II study assessed MK-0457 (tozasertib) monotherapy in patients with CML-CP and a T315I mutation [126]. Two of 15 patients (13.3\%) with CML-CP achieved an MCyR. However, the response was minimal and was achieved only at higher, less-tolerable doses [126]. A phase I study assessed PHA-739358 (danusertib) monotherapy in patients with CML-AP/BC or Ph + ALL resistant or intolerant to imatinib and/or a 2GTKI. Four of 29 (13.8\%) patients, all of whom had the T315I mutation, exhibited a hematologic response [127].

\section{BCL-2 inhibitors}

B cell lymphoma protein 2, BCL-2, is a regulator of apoptosis and a potential target for CML therapy. Venetoclax, a BCL-2 inhibitor, has been tested for use in CML in the preclinical setting and has demonstrated increased apoptosis $[128,129]$. In a retrospective study of patients with $\mathrm{Ph}+\mathrm{ALL}$ and CML-BP, $50 \%$ of patients receiving venetoclax in combination with a TKI had a response [130].

\section{Conclusion}

The development of TKI therapy has greatly improved the prognosis of patients with CML, allowing a shift in treatment goals from increasing survival to improving quality of life and attempting TFR [3-6, 8, 9]. However, despite these advances, $30-50 \%$ of patients experience failure of frontline imatinib therapy after 5 years, and many even when treated with frontline 2GTKIs; resistance rates are even higher for patients on $2 \mathrm{~L}$ therapy, with $63-72 \%$ failing to achieve MMR with 2 years of follow-up [10, 16, 17, 24-26, 36]. Treatment guidelines for patients failing $2 \mathrm{~L}$ therapy are lacking; little data have shown clinical benefit to switching to a different 2GTKI in the $3 \mathrm{~L}$ setting $[4,5]$. Therapies in development focus largely on new BCR-ABL1 TKI options, mostly ATPcompetitive agents with some attractive early results in clinical trials. One new class has emerged, represented by asciminib, a novel first-in-class STAMP inhibitor. Asciminib has shown promising early-phase data and may help address unmet medical needs in later lines of therapy, such as resistance and intolerance [77, 79, 80]. Other pathways are being investigated as potential targets for CML, including immune signaling [105, 106] and the JAK/STAT [110-112] and mTOR [98, 121] pathways. Development of effective therapies for patients who fail 2L TKI therapies is still a critical unmet need for CML.

\begin{abstract}
Abbreviations
1L: First line; 2G: Second generation; 2GTKI: Second-generation tyrosine kinase inhibitor; 2L: Second line; 3G: Third generation; 3L: Third line; AE: Adverse event; ALL: Acute lymphoid leukemia; allo-SCT: Allogeneic stem cell transplant; AOE: Arterio-occlusive event; AP: Accelerated phase; ATP: Adenosine triphosphate; BID: Twice a day; BP: Blast phase; CCHR: Cumulative confirmed complete hematologic response; CCyR: Complete cytogenetic response; CHR: Complete hematologic response; CML: Chronic myeloid leukemia; CP: Chronic phase; CyR: Cytogenetic response; DLT: Dose-limiting toxicity; DMR: Deep molecular response; EFS: Event-free survival; ELN: European LeukemiaNet; KM: Kaplan-Meier; LSC: Leukemia stem cell; MCyR: Major cytogenetic response; MMR: Major molecular response; MR 4 : 4.0-Log molecular response (BCR$\left.A B L 7^{15} \leq 0.01 \%\right) ; M R^{4.5}: 4.5$-Log molecular response $\left(B C R-A B L 7^{15} \leq 0.0032 \%\right)$; MTD: Maximum tolerated dose; NCCN: National Comprehensive Cancer Network; OS: Overall survival; PCyR: Partial cytogenetic response; PD-1: Programmed cell death 1 protein; PD-L1: Programmed cell death 1 ligand 1; PFS: Progression-free survival; Ph+: Philadelphia chromosome positive; QD: Once a day; RDE: Recommended dose for expansion; RP2D: Recommended phase 2 dose; STAMP: Specifically Targeting the ABL Myristoyl Pocket; TEAE: Treatmentemergent adverse event; TFR: Treatment-free remission; TKI: Tyrosine kinase inhibitor.
\end{abstract}

\section{Acknowledgements}

Financial support for medical editorial assistance was provided by Novartis. We thank Rohini Roy, Ph.D. and Michelle Chadwick, Ph.D. (Nucleus Global), for medical editorial assistance with this manuscript.

\section{Authors' contributions}

$J \mathrm{C}$ and $\mathrm{FL}$ contributed equally to the writing of this manuscript. Both authors read and approved the final manuscript. 


\section{Funding}

The authors received funding from Novartis for editorial support in the writing of this review.

\section{Availability of data and materials}

Not applicable.

\section{Declarations}

Ethics approval and consent to participate

Not applicable.

\section{Consent for publication}

Not applicable.

\section{Competing interests}

The authors received nonfinancial support (assistance with manuscript preparation) from Nucleus Global, which received funding from Novartis Pharmaceuticals Corporation. JC served as a consultant for Novartis, Pfizer, and Takeda and received research funds from Novartis, Pfizer, Takeda, and Sun Pharma. FL served as a consultant for Novartis, Bristol Myers Squibb, Celgene, and Incyte; received research funds from Novartis; and received honoraria from Novartis, Bristol Myers Squibb, Celgene, and Incyte.

\section{Author details}

${ }^{1}$ Georgia Cancer Center at Augusta University, 1410 Laney Walker Rd., CN2222, Augusta, GA 30912, USA. ${ }^{2}$ Department of Medicine, Hematology and Oncology, Goethe University Hospital, Building 33, 3rd floor, Room 246, Theodor-Stern-Kai 7, 60590 Frankfurt a. Main, Germany.

Received: 6 January 2021 Accepted: 1 March 2021

Published online: 18 March 2021

\section{References}

1. Faderl S, Talpaz M, Estrov Z, O'Brien S, Kurzrock R, Kantarjian HM. The biology of chronic myeloid leukemia. N Engl J Med. 1999;341:164-72.

2. Soverini S, Bassan R, Lion T. Treatment and monitoring of Philadelphia chromosome-positive leukemia patients: recent advances and remaining challenges. J Hematol Oncol. 2019;12:39.

3. Bower H, Bjorkholm M, Dickman PW, Hoglund M, Lambert PC, Andersson TM. Life expectancy of patients with chronic myeloid leukemia approaches the life expectancy of the general population. J Clin Oncol. 2016;34:2851-7.

4. National Comprehensive Cancer Network. NCCN: clinical practice guidelines in oncology. Chronic Myeloid Leukemia V2.2021.

5. Hochhaus A, Baccarani M, Silver RT, Schiffer C, Apperley JF, Cervantes F, et al. European LeukemiaNet 2020 recommendations for treating chronic myeloid leukemia. Leukemia. 2020;34:966-84.

6. Baccarani M, Deininger MW, Rosti G, Hochhaus A, Soverini S, Apperley $J F$, et al. European LeukemiaNet recommendations for the management of chronic myeloid leukemia: 2013. Blood. 2013;122:872-84.

7. Hochhaus A, Saussele S, Rosti G, Mahon FX, Janssen JJWM, Hjorth Hansen $\mathrm{H}$, et al. Chronic myeloid leukemia: EMSO clinical practice guidelines for diagnosis, treatment, and follow-up. Ann Oncol. 2017:28(suppl 4):iv41-51.

8. Hughes TP, Ross DM. Moving treatment-free remission into mainstream clinical practice in CML. Blood. 2016;128:17-23.

9. Cortes J, Rea D, Lipton JH. Treatment-free remission with first- and second-generation tyrosine kinase inhibitors. Am J Hematol. 2019;94:346-57.

10. Hehlmann R, Müller MC, Lauseker M, Hanfstein B, Fabarius A, Schreiber $A$, et al. Deep molecular response is reached by the majority of patients treated with imatinib, predicts survival, and is achieved more quickly by optimized high-dose imatinib: results from the randomized CML-Study IV. J Clin Oncol. 2014;32:415-23.

11. Akard LP, Albitar M, Hill CE, Pinilla-lbarz J. The, "hit hard and hit early" approach to the treatment of chronic myeloid leukemia: implications of the updated National Comprehensive Cancer Network clinical practice guidelines for routine practice. Clin Adv Hematol Oncol. 2013;11:421-32.

12. Hehlmann R. Chronic myeloid leukemia in 2020. Hemasphere. 2020;4(5):e468.

13. Hochhaus A, Saglio G, Hughes TP, Larson RA, Kim DW, Issaragrisil S, et al. Long-term benefits and risks of frontline nilotinib vs imatinib for chronic myeloid leukemia in chronic phase: 5-year update of the randomized ENESTnd trial. Leukemia. 2016;30:1044-54.

14. Cortes JE, Mauro MJ, Deininger MW, Chuah C, Kim D, Kota V, et al. Bosutinib vs imatinib for newly diagnosed chronic myeloid leukemia in the BFORE trial: 24-month follow-up. J Clin Oncol. 2018;36 (Abstract: 7002).

15. Brümmendorf TH, Cortes JE, Milojkovic D, Gambacorti-Passerini C, Clark $\mathrm{RE}$, le Coutre PD, et al. Bosutinib (BOS) versus imatinib for newly diagnosed chronic phase (CP) chronic myeloid leukemia (CML): final 5-year results from the Bfore trial. Blood. 2020;136(suppl 1):41-2.

16. Hochhaus A, Saglio G, Hughes TP, Larson RA, Kim DW, Issaragrisil S, et al. Long-term benefits and risks of frontline nilotinib vs imatinib for chronic myeloid leukemia in chronic phase: 5-year update of the randomized ENESTnd trial. Leukemia. 2016:30(5):1044-54.

17. Cortes JE, Saglio G, Kantarjian HM, Baccarani M, Mayer J, Boque C, et al. Final 5-year study results of DASISION: the dasatinib versus imatinib study in treatment-naive chronic myeloid leukemia patients trial. J Clin Oncol. 2016:34:2333-40.

18. Cortes JE, Khoury HJ, Kantarjian HM, Lipton JH, Kim DW, Schafhausen P, et al. Long-term bosutinib for chronic phase chronic myeloid leukemia after failure of imatinib plus dasatinib and/or nilotinib. Am J Hematol. 2016;91:1206-14.

19. Cortes JE, Kim DW, Pinilla-Ibarz J, le Coutre PD, Paquette R, Chuah C, et al. Ponatinib efficacy and safety in Philadelphia chromosomepositive leukemia: final 5-year results of the phase 2 PACE trial. Blood. 2018;132:393-404.

20. Shah NP, Guilhot F, Cortes JE, Schiffer CA, le Coutre P, Brummendorf $\mathrm{TH}$, et al. Long-term outcome with dasatinib after imatinib failure in chronic-phase chronic myeloid leukemia: follow-up of a phase 3 study. Blood. 2014;123:2317-24

21. Giles FJ, le Coutre PD, Pinilla-Ibarz J, Larson RA, Gattermann N, Ottmann $\mathrm{OG}$, et al. Nilotinib in imatinib-resistant or imatinib-intolerant patients with chronic myeloid leukemia in chronic phase: 48-month follow-up results of a phase II study. Leukemia. 2013;27:107-12.

22. Smith BD, Brümmendorf T, Roboz G, Gambacorti Passerini C, Charbonnier A, Viqueira E, et al. Efficacy of bosutinib in imatinib-resistant vs dasatinib/nilotinib-resistant chronic phase chronic myeloid leukemia: results from the phase 4 BYOND study. Blood. 2019;134(Suppl 1):1650 (Abstract: 632)

23. Gambacorti-Passerini C, Aroldi A, Cordani N, Piazza R. Chronic myeloid leukemia: second-line drugs of choice. Am J Hematol. 2016:91:67-75.

24. Kantarjian HM, Giles FJ, Bhalla KN, Pinilla-lbarz J, Larson RA, Gattermann $\mathrm{N}$, et al. Nilotinib is effective in patients with chronic myeloid leukemia in chronic phase after imatinib resistance or intolerance: 24-month follow-up results. Blood. 2011;117:1141-5.

25. Shah NP, Kim DW, Kantarjian H, Rousselot P, Llacer PE, Enrico A, et al. Potent, transient inhibition of BCR-ABL with dasatinib $100 \mathrm{mg}$ daily achieves rapid and durable cytogenetic responses and high transformation-free survival rates in chronic phase chronic myeloid leukemia patients with resistance, suboptimal response or intolerance to imatinib. Haematologica. 2010;95:232-40.

26. Gambacorti-Passerini C, BrümmendorfTH, Kim DW, Turkina AG, Masszi $T$, Assouline $S$, et al. Bosutinib efficacy and safety in chronic phase chronic myeloid leukemia after imatinib resistance or intolerance: minimum 24-month follow-up. Am J Hematol. 2014;89:732-42.

27. Garg RJ, Kantarjian H, O'Brien S, Quintas-Cardama A, Faderl S, Estrov $Z$, et al. The use of nilotinib or dasatinib after failure to 2 prior tyrosine kinase inhibitors: long-term follow-up. Blood. 2009;114:4361-8.

28. Steegmann JL, Baccarani M, Breccia M, Casado LF, Garcia-Gutierrez V, Hochhaus A, et al. European LeukemiaNet recommendations for the management and avoidance of adverse events of treatment in chronic myeloid leukaemia. Leukemia. 2016;30:1648-71.

29. Hantschel O, Rix U, Superti-Furga G. Target spectrum of the BCR$A B L$ inhibitors imatinib, nilotinib and dasatinib. Leuk Lymphoma. 2008:49:615-9. 
30. Tasigna (nilotinib) [package insert]. East Hanover, NJ: Novartis Pharmaceuticals Corporation; 2019.

31. Gleevec (imatinib) [package insert]. East Hanover, NJ: Novartis Pharmaceuticals Corporation; 2018.

32. Sprycel (dasatinib) [package insert]. Princeton, NJ: Bristol-Myers Squibb Company; 2018.

33. Deangelo DJ. Managing chronic myeloid leukemia patients intolerant to tyrosine kinase inhibitor therapy. Blood Cancer J. 2012;2:e95.

34. Cortes JE, Hochhaus A, le Coutre PD, Rosti G, Pinilla-Ibarz J, Jabbour E, et al. Minimal cross-intolerance with nilotinib in patients with chronic myeloid leukemia in chronic or accelerated phase who are intolerant to imatinib. Blood. 2011:117:5600-6.

35. Kobayashi Y, Sakamaki H, Fujisawa S, Ando K, Yamamoto K, Okada $M$, et al. Lack of non-hematological cross intolerance of dasatinib to imatinib in imatinib-intolerant patients with Philadelphia chromosome positive chronic myeloid leukemia or acute lymphatic leukemia: a retrospective safety analysis. Int J Hematol. 2011;93:745-9.

36. Garcia-Gutierrez V, Hernandez-Boluda JC. Tyrosine kinase inhibitors available for chronic myeloid leukemia: efficacy and safety. Front Oncol. 2019;9:603.

37. Khoury HJ, Goldberg SL, Mauro MJ, Stone RM, Deininger MW, BradleyGarelik MB, et al. Cross-intolerance with dasatinib among imatinibintolerant patients with chronic phase chronic myeloid leukemia. Clin Lymphoma Myeloma Leuk. 2016;16:341-9.

38. Iclusig (ponatinib) [package insert]. Cambridge, MA: Takeda Pharmaceutical Company Limited; 2020 .

39. Soverini S, Gnani A, Colarossi S, Castagnetti F, Abruzzese E, Paolini $\mathrm{S}$, et al. Philadelphia-positive patients who already harbor imatinibresistant Bcr-Abl kinase domain mutations have a higher likelihood of developing additional mutations associated with resistance to secondor third-line tyrosine kinase inhibitors. Blood. 2009:114:2168-71.

40. Jabbour E, Kantarjian H. Chronic myeloid leukemia: 2018 update on diagnosis, therapy and monitoring. Am J Hematol. 2018;93:442-59.

41. Soverini S, Branford S, Nicolini FE, Talpaz M, Deininger MW, Martinelli G, et al. Implications of BCR-ABL1 kinase domain-mediated resistance in chronic myeloid leukemia. Leuk Res. 2014;38:10-20.

42. Eide CA, Zabriskie MS, Savage Stevens SL, Antelope O, Vellore NA, Than $\mathrm{H}$, et al. Combining the allosteric inhibitor asciminib with ponatinib suppresses emergence of and restores efficacy against highly resistant BCR-ABL1 mutants. Cancer Cell. 2019;36:431-43e5.

43. Zabriskie MS, Eide CA, Tantravahi SK, Vellore NA, Estrada J, Nicolini FE, et al. BCR-ABL1 compound mutations combining key kinase domain positions confer clinical resistance to ponatinib in Ph chromosomepositive leukemia. Cancer Cell. 2014;26:428-42.

44. Redaelli S, Mologni L, Rostagno R, Piazza R, Magistroni V, Ceccon M, et al. Three novel patient-derived BCR/ABL mutants show different sensitivity to second and third generation tyrosine kinase inhibitors. Am J Hematol. 2012;87:E125-8.

45. Jabbour E, Kantarjian H. Chronic myeloid leukemia: 2020 update on diagnosis, therapy and monitoring. Am J Hematol. 2020;95:691-709.

46. Cortes JE, Kim DW, Pinilla-lbarz J, le Coutre P, Paquette R, Chuah C et al. A phase 2 trial of ponatinib in Philadelphia chromosome-positive leukemias. N Engl J Med. 2013:369(19):1783-96.

47. Gandhi V, Plunkett W, Cortes JE. Omacetaxine: a protein translation inhibitor for treatment of chronic myelogenous leukemia. Clin Cancer Res. 2014;20:1735-40.

48. Damlaj M, Lipton JH, Assouline SE. A safety evaluation of omacetaxine mepesuccinate for the treatment of chronic myeloid leukemia. Expert Opin Drug Saf. 2016;15:1279-86.

49. Synribo (omacetaxin mepesuccinate) [package insert]. North Wales, PA: Teva Pharmaceuticals USA, Inc.; 2019.

50. Cortes JE, Kantarjian HM, Rea D, Wetzler M, Lipton JH, Akard L, et al. Final analysis of the efficacy and safety of omacetaxine mepesuccinate in patients with chronic- or accelerated-phase chronic myeloid leukemia: results with 24 months of follow-up. Cancer. 2015;121:1637-44.

51. Radich J. Stem cell transplant for chronic myeloid leukemia in the imatinib era. Semin Hematol. 2010;47:354-61.

52. Lomaia E, Zaritskey A, Shuvaev V, Martynkevich I, Fominykh M, Ovsyannikova $E$, et al. Efficacy of tyrosine kinase inhibitors in third line therapy in chronic phase chronic myeloid leukemia. Blood. 2015;126:4051.
53. Loscocco F Visani G, Galimberti S, Curti A, Isidori A. BCR-ABL independent mechanisms of resistance in chronic myeloid leukemia. Front Oncol. 2019:9:939.

54. Cortes J, Jabbour E, Kantarjian H, Yin CC, Shan J, O'Brien S, et al. Dynamics of BCR-ABL kinase domain mutations in chronic myeloid leukemia after sequential treatment with multiple tyrosine kinase inhibitors. Blood. 2007;110(12):4005-11.

55. Bosi GR, Fogliatto LM, Costa TEV, Grokoski KC, Pereira MP, Bugs N, et al. What happens to intolerant, relapsed or refractory chronic myeloid leukemia patients without access to clinical trials? Hematol Transfus Cell Ther. 2019:41:222-8.

56. Giles FJ, Abruzzese E, Rosti G, Kim DW, Bhatia R, Bosly A, et al. Nilotinib is active in chronic and accelerated phase chronic myeloid leukemia following failure of imatinib and dasatinib therapy. Leukemia. 2010;24:1299-301.

57. Ibrahim AR, Paliompeis C, Bua M, Milojkovic D, Szydlo R, Khorashad JS, et al. Efficacy of tyrosine kinase inhibitors (TKIs) as third-line therapy in patients with chronic myeloid leukemia in chronic phase who have failed 2 prior lines of TKI therapy. Blood. 2010;116:5497-500.

58. Russo Rossi A, Breccia M, Abruzzese E, Castagnetti F, Luciano L, Gozzini $A$, et al. Outcome of 82 chronic myeloid leukemia patients treated with nilotinib or dasatinib after failure of two prior tyrosine kinase inhibitors. Haematologica. 2013;98:399-403.

59. Ribeiro BF, Miranda EC, Albuquerque DM, Delamain MT, Oliveira-Duarte $\mathrm{G}$, Almeida $\mathrm{MH}$, et al. Treatment with dasatinib or nilotinib in chronic myeloid leukemia patients who failed to respond to two previously administered tyrosine kinase inhibitors-a single center experience. Clinics (Sao Paulo). 2015;70:550-5.

60. Cortes J, Digumarti R, Parikh PM, Wetzler M, Lipton JH, Hochhaus A, et al. Phase 2 study of subcutaneous omacetaxine mepesuccinate for chronic-phase chronic myeloid leukemia patients resistant to or intolerant of tyrosine kinase inhibitors. Am J Hematol. 2013;88:350-4.

61. Cortes J, Lipton JH, Rea D, Digumarti R, Chuah C, Nanda N, et al. Phase 2 study of subcutaneous omacetaxine mepesuccinate after TKI failure in patients with chronic-phase CML with T315I mutation. Blood. 2012;120(2573-80):62.

62. Brümmendorf TH, Cortez JE, Goh YT, Yilmaz M, Klisovic RB, Purcell $\mathrm{S}$, et al. Bosutinib for previously treated patients with Philadelphia chromosome-positive leukemia: $\geq 8$-year update of a phase 1/2 Study. ASH; 2020; Virtual.

63. Cortes JE, Lomaia E, Turkina A, Moiraghi B, Sutton MU, Pavlovsky C, et al. Interim analysis (IA) of OPTIC: a dose-ranging study of three ponatinib (PON) starting doses. J Clin Oncol. 2020;38(15):7502.

64. Jiang Q, Huang X, Chen Z, Niu Q, Men L, Wang H, et al. An updated safety and efficacy results of phase 1 study of HQP1351, a novel 3rd generation of BCR-ABL tyrosine kinase inhibitor (TKI), in patients with TKI resistant chronic myeloid leukemia. Blood. 2019;134:493.

65. Jiang Q, Huang XJ, Men L, Liu W, Sun X, Ji J, et al. Safety and efficacy of HQP1351, a 3rd generation oral BCR-ABL inhibitor in patients with tyrosine kinase inhibitor-resistant chronic myelogenous leukemia: preliminary results of phase I study. Blood. 2018:132(suppl 1):791.

66. Ren X, Pan X, Zhang Z, Wang D, Lu X, Li Y, et al. Identification of GZD824 as an orally bioavailable inhibitor that targets phosphorylated and nonphosphorylated breakpoint cluster region-Abelson (Bcr-Abl) kinase and overcomes clinically acquired mutation-induced resistance against imatinib. J Med Chem. 2013;56:879-94.

67. Lu M, Deng C, Xiong Y, Wang H, Xu P, Men L, et al. Exposure-response (E-R) analysis of olverembatinib (HQP1351) in Chinese patients with chronic myeloid leukemia (CML). Blood. 2020;136:5-6.

68. Jiang Q, Huang X, Chen Z, Niu Q, Shi D, Li Z, et al. Novel BCR-ABL1 tyrosine kinase inhibitor (TKI) HQP1351 (olverembatinib) is efficacious and well tolerated in patients with T315l-mutated chronic myeloid leukemia (CML): results of pivotal (phase II) trials. Blood. 2020;136:50-1.

69. Mian AA, Rafiei A, Haberbosch I, Zeifman A, Titov I, Stroylov V, et al. PF-114, a potent and selective inhibitor of native and mutated BCR/ABL is active against Philadelphia chromosome-positive $(\mathrm{Ph}+)$ leukemias harboring the T315I mutation. Leukemia. 2015;29:1 104-14.

70. Turkina A, Vinogradova O, Lomaia E, Shatokhina E, Shukhov O, Chelysheva E, et al. PF-1 14: a 4th generation tyrosine kinase-inhibitor for chronic phase chronic myeloid leukaemia including BCRABL1T315I. Blood. 2019:134:1638. 
71. Turkina A, Vinogradova O, Lomaia E, Shatokhina E, Shukhov O, Chelysheva E, et al. Phase-1 study of PF-114 mesylate in CML failing prior tyrosine kinase-inhibitor therapy. Blood. 2018;132:790.

72. ClinicalTrials.gov. Study to evaluate tolerability, safety, pharmacokinetics andpreliminary efficacy of PF-114 for oral administration in adults with $\mathrm{Ph}+$ chronic myeloidleukemia, which is resistant to the 2 nd generation Bcr-Abl inhibitors or has T315I mutation in the BCR-ABL gene. https:// clinicaltrials.gov/ct2/show/NCT02885766. Accessed 20 June 2020.

73. Antelope O, Vellore NA, Pomicter AD, Patel AB, Van Scoyk A, Clair PM, et al. BCR-ABL1 tyrosine kinase inhibitor K0706 exhibits preclinical activity in Philadelphia chromosome-positive leukemia. Exp Hematol. 2019;77(36-40):e2.

74. Cortes JE, Kim D, Nicolini FE, Saikia T, Charbonnier A, Apperley JF, et al. Phase 1 trial of K0706, a novel oral BCR-ABL1 tyrosine kinase inhibitor (TKI): in patients with chronic myelogenous leukemia (CML) and Phildelphia positive acute lymphoblastic leukemia (Ph+ ALL) failing $\geq$ 3 prior TKI therapies: initial safety and efficacy. Blood. 2019;134:4158.

75. ClinicalTrials.gov. Safety, tolerability, pharmacokinetics and activity of K0706. https://clinicaltrials.gov/ct2/show/NCT02629692. Accessed 20 June 2020.

76. Cortes JE, Saikia T, Kim D-W, Alvarado Y, Nicolini FE, Khattry N, et al. Phase 1 trial of vodobatinib, a novel oral BCR-ABL1 tyrosine kinase inhibitor (TKI): activity in CML chronic phase patients failing TKI therapies including ponatinib. Blood. 2020;136:51-2.

77. Hughes T, Mauro MJ, Kim D, Cortes J, Rea D, Minami H, et al. Asciminib in heavily pretreated patients with Ph+CML-CP sensitive to TKI therapy. EHA 25 Library. 2020 (Abstract: S170)

78. Manley PW, Barys L, Cowan-Jacob SW. The specificity of asciminib, a potential treatment for chronic myeloid leukemia, as a myristate-pocket binding $A B L$ inhibitor and analysis of its interactions with mutant forms of BCR-ABL1 kinase. Leuk Res. 2020;98:106458.

79. Schoepfer J, Jahnke W, Berellini G, Buonamici S, Cotesta S, Cowan-Jacob SW, et al. Discovery of asciminib (ABL001), an allosteric inhibitor of the tyrosine kinase activity of BCR-ABL1. J Med Chem. 2018;61 (18):8120-35.

80. Wylie AA, Schoepfer J, Jahnke W, Cowan-Jacob SW, Loo A, Furet P, et al. The allosteric inhibitor ABL001 enables dual targeting of BCR-ABL1. Nature. 2017;543:733-7.

81. Hughes TP, Mauro MJ, Cortes JE, Minami H, Rea D, DeAngelo DJ, et al. Asciminib in chronic myeloid leukemia after ABL kinase inhibitor failure. N Engl J Med. 2019;381:2315-26.

82. ClinicalTrials.gov. Study of efficacy of CML-CP patients treated with ABL001 versus bosutinib, previously treated with 2 or more TKIs. https:// clinicaltrials.gov/ct2/show/NCT03106779. Accessed 2 Dec 2020.

83. ClinicalTrials.gov. Study of efficacy and safety of asciminib in combination with imatinib in patients with chronic myeloid leukemia in chronic phase (CML-CP). https://clinicaltrials.gov/ct2/show/NCT03578367. Accessed 2 Dec 2020.

84. ClinicalTrials.gov. ABL001 for the treatment of chronic myeloid leukemia in patients who are on therapy with tyrosine kinase inhibitor. https:// clinicaltrials.gov/ct2/show/NCT04216563. Accessed 2 Dec 2020.

85. ClinicalTrials.gov. Frontline asciminib combination in chronic phase CML (CMLXI). https://clinicaltrials.gov/ct2/show/NCT03906292. Accessed 2 Dec 2020.

86. ClinicalTrials.gov. A phase I study of oral ABL001 in patients with CML or $\mathrm{Ph}+\mathrm{ALL}$. https://clinicaltrials.gov/ct2/show/NCT02081378. Accessed 2 Dec 2020.

87. ClinicalTrials.gov. Study of efficacy and safety of asciminib in combination with imatinib in patients with chronic myeloid leukemia in chronic phase (CML-CP). https://clinicaltrials.gov/ct2/show/NCT03578367. Accessed 15 Dec 2020.

88. ClinicalTrials.gov. ABL001 + dasatinib + prednisone in BCR-ABL+ B-ALL or CML. https://clinicaltrials.gov/ct2/show/NCT03595917. Accessed 15 Dec 2020.

89. ClinicalTrials.gov. Frontline asciminib combination in chronic phase CML (CMLXI). https://clinicaltrials.gov/ct2/show/NCT03906292. Accessed 15 Dec 2020.

90. Cortes J, Lang F, Kim D, Rea D, Mauro MJ, Minami H, et al. Combination therapy using asciminib plus imatinib (IMA) in patients (Pts) with chronic myeloid leukemia (CML): results from a phase 1 study. EHA. 2019 (Abstract: S883).
91. Mauro MJ, Kim D, Cortes J, Rea D, Hughes TP, Minami H, et al. Combination of asciminib plus nilotinib (Nil) or dasatinib (Das) in patients (Pts) with chronic myeloid leukemia (CML): results from a phase 1 study. EHA. 2019 (Abstract: S884).

92. Cortes JE, Hughes TP, Mauro MJ, Hochhaus A, Rea D, Goh YT, et al. Asciminib, a first-in-class STAMP inhibitor, provides durable molecular response in patients (pts) with chronic myeloid leukemia (CML) harboring the T315I mutation: primary efficacy and safety results from a phase 1 trial. Blood. 2020;136:47-50.

93. Hochhaus A, Boquimpani C, Rea D, Minami Y, Lomaia E, Voloshin S, et al. Efficacy and safety results from ASCEMBL, a multicenter, open-label, phase 3 study of asciminib, a first-in-class STAMP inhibitor, vs bosutinib (BOS) in patients (Pts) with chronic myeloid leukemia in chronic phase (CML-CP) previously treated with $\geq 2$ tyrosine kinase inhibitors (TKIs). Blood. 2020;136:LBA-4.

94. Muselli F, Peyron JF, Mary D. Druggable biochemical pathways and potential therapeutic alternatives to target leukemic stem cells and eliminate the residual disease in chronic myeloid leukemia. Int J Mol Sci. 2019;20(22):5616.

95. Bhatia R. Novel approaches to therapy in CML. Hematology Am Soc Hematol Educ Program. 2017;2017(1):115-20.

96. Özgür Yurttaş N, Eşkazan AE. Novel therapeutic approaches in chronic myeloid leukemia. Leuk Res. 2020;91:106337.

97. Holyoake TL, Vetrie D. The chronic myeloid leukemia stem cell: stemming the tide of persistence. Blood. 2017;129(12):1595-606.

98. Massimino M, Stella S, Tirrò E, Romano C, Pennisi MS, Puma A, et al. Non ABL-directed inhibitors as alternative treatment strategies for chronic myeloid leukemia. Mol Cancer. 2018;17(1):56.

99. Houshmand M, Simonetti G, Circosta P, Gaidano V, Cignetti A, Martinelli G, et al. Chronic myeloid leukemia stem cells. Leukemia. 2019:33(7):1543-56.

100. Hamilton A, Helgason GV, Schemionek M, Zhang B, Myssina S, Allan EK, et al. Chronic myeloid leukemia stem cells are not dependent on BcrAbl kinase activity for their survival. Blood. 2012;119(6):1501-10.

101. Corbin AS, Agarwal A, Loriaux M, Cortes J, Deininger MW, Druker BJ. Human chronic myeloid leukemia stem cells are insensitive to imatinib despite inhibition of BCR-ABL activity. J Clin Investig. 2011;121(1):396-409.

102. Westerweel PE, Te Boekhorst PAW, Levin MD, Cornelissen JJ. New approaches and treatment combinations for the management of chronic myeloid leukemia. Front Oncol. 2019;9:665.

103. ClinicalTrials.gov. Long-acting low dose ropeginterferon for chronic myeloid leukemia treated with bosutinib from diagnosis (BosuPeg). https://clinicaltrials.gov/ct2/show/NCT03831776. Accessed 2 Dec 2020.

104. Christiansson L, Soderlund S, Svensson E, Mustjoki S, Bengtsson M, Simonsson B, et al. Increased level of myeloid-derived suppressor cells, programmed death receptor ligand 1/programmed death receptor 1, and soluble CD25 in Sokal high risk chronic myeloid leukemia. PLoS ONE. 2013;8(1):e55818.

105. ClinicalTrials.gov. A phase $1 B$ study to investigate the safety and preliminary efficacy for the combination of dasatinib plus nivolumab in patients with chronic myeloid leukemia. https://clinicaltrials.gov/ct2/ show/NCT02011945. Accessed 2 Dec 2020.

106. ClinicalTrials.gov. Therapies in combination or sequentially with tyrosine kinase inhibitors (TKIs) in chronic phase chronic myelogenous leukemia patients in CCR (ACTIW) (ACTIW). https://clinicaltrials.gov/ct2/show/ NCT02767063. Accessed 2 Dec 2020.

107. Prost S, Relouzat F, Spentchian M, Ouzegdouh Y, Saliba J, Massonnet $\mathrm{G}$, et al. Erosion of the chronic myeloid leukaemia stem cell pool by PPARgamma agonists. Nature. 2015;525(7569):380-3.

108. Herrmann H, Sadovnik I, Cerny-Reiterer S, Rulicke T, Stefanzl G, Willmann $M$, et al. Dipeptidylpeptidase IV (CD26) defines leukemic stem cells (LSC) in chronic myeloid leukemia. Blood. 2014;123(25):3951-62.

109. Clinicaltrialsregister.eu. Dipeptidylpeptidase IV (CD26) on Philadelphiapositive leukemic stem cells (LSC) as marker and novel therapeutic target in chronic myeloid leukemia (CML). https://www.clinicaltrialsr egister.eu/ctr-search/search?query=2017-000899-28. Accessed 2 Dec 2020.

110. Gallipoli P, Cook A, Rhodes S, Hopcroft L, Wheadon H, Whetton AD, et al. JAK2/STAT5 inhibition by nilotinib with ruxolitinib contributes 
to the elimination of CML CD34+ cells in vitro and in vivo. Blood. 2014;124(9):1492-501.

111. Sweet K, Hazlehurst L, Sahakian E, Powers J, Nodzon L, Kayali F, et al. A phase I clinical trial of ruxolitinib in combination with nilotinib in chronic myeloid leukemia patients with molecular evidence of disease. Leuk Res. 2018;74:89-96.

112. ClinicalTrials.gov. Testing the addition of ruxolitinib to the usual treatment (tyrosine kinase inhibitors) for chronic myeloid leukemia 2020. https://clinicaltrials.gov/ct2/show/NCT03654768. Accessed 2 Dec 2020

113. Zhou H, Mak PY, Mu H, Mak DH, Zeng Z, Cortes J, et al. Combined inhibition of $\beta$-catenin and Bcr-Abl synergistically targets tyrosine kinase inhibitor-resistant blast crisis chronic myeloid leukemia blasts and progenitors in vitro and in vivo. Leukemia. 2017:31(10):2065-74.

114. ClinicalTrials.gov. Safety and efficacy study of PRI-724 in subjects with advanced myeloid malignancies. https://clinicaltrials.gov/ct2/show/ NCT01606579. Accessed 2 Dec 2020

115. Ohanian M, Tari Ashizawa A, Garcia-Manero G, Pemmaraju N, Kadia T, Jabbour E, et al. Liposomal Grb2 antisense oligodeoxynucleotide (BP1001) in patients with refractory or relapsed haematological malignancies: a single-centre, open-label, dose-escalation, phase $1 / 1 \mathrm{~b}$ trial. Lancet Haematol. 2018;5(4):e136-46.

116. Naka K, Hoshii T, Muraguchi T, Tadokoro Y, Ooshio T, Kondo Y, et al. TGFbeta-FOXO signalling maintains leukaemia-initiating cells in chronic myeloid leukaemia. Nature. 2010;463(7281):676-80.

117. Ahmed W, Van Etten RA. Signal transduction in the chronic leukemias: implications for targeted therapies. Curr Hematol Malig Rep. 2013;8(1):71-80.

118. Cortes J, Quintás-Cardama A, Garcia-Manero G, O'Brien S, Jones D, Faderl $\mathrm{S}$, et al. Phase 1 study of tipifarnib in combination with imatinib for patients with chronic myelogenous leukemia in chronic phase after imatinib failure. Cancer. 2007:110(9):2000-6.

119. Cortes J, Jabbour E, Daley GQ, O'Brien S, Verstovsek S, Ferrajoli A, et al. Phase 1 study of lonafarnib (SCH 66336) and imatinib mesylate in patients with chronic myeloid leukemia who have failed prior singleagent therapy with imatinib. Cancer. 2007;110(6):1295-302.

120. Copland M, Pellicano F, Richmond L, Allan EK, Hamilton A, Lee FY, et al. BMS-214662 potently induces apoptosis of chronic myeloid leukemia stem and progenitor cells and synergizes with tyrosine kinase inhibitors. Blood. 2008;111(5):2843-53.

121. Dinner S, Platanias LC. Targeting the mTOR pathway in leukemia. J Cell Biochem. 2016;117(8):1745-52.

122. Zhang B, StrausS AC, Chu S, Li M, Ho Y, Shiang KD, et al. Effective targeting of quiescent chronic myelogenous leukemia stem cells by histone deacetylase inhibitors in combination with imatinib mesylate. Cancer Cell. 2010;17(5):427-42.

123. Zaritskey A, Alimena G, Konopka L, Shamsazar J, Bourquelot PM, Jalaluddin M, et al. A phase Il study of oral panobinostat (LBH589) for chronic phase chronic myeloid leukemia (CML) with resistance to $\geq 2$ BCR-ABL tyrosine kinase inhibitors. Blood. 2008;112(11):4254.

124. Maiti A, Cortes JE, Brown YD, Kantarjian HM. Phase I/II study of lowdose azacytidine in patients with chronic myeloid leukemia who have minimal residual disease while receiving therapy with tyrosine kinase inhibitors. Leuk Lymphoma. 2017;58(3):722-5.
125. Abaza Y, Kantarjian H, Alwash Y, Borthakur G, Champlin R, Kadia T, et al. Phase $1 / / I$ study of dasatinib in combination with decitabine in patients with accelerated or blast phase chronic myeloid leukemia. Am J Hematol. 2020;95(11):1288-95.

126. Seymour JF, Kim DW, Rubin E, Haregewoin A, Clark J, Watson P, et al. A phase 2 study of MK-0457 in patients with BCR-ABL T315I mutant chronic myelogenous leukemia and Philadelphia chromosome-positive acute lymphoblastic leukemia. Blood Cancer J. 2014;4(8):e238.

127. Borthakur G, Dombret H, Schafhausen P, Brummendorf TH, Boissel N, Jabbour E, et al. A phase I study of danusertib (PHA-739358) in adult patients with accelerated or blastic phase chronic myeloid leukemia and Philadelphia chromosome-positive acute lymphoblastic leukemia resistant or intolerant to imatinib and/or other second generation c-ABL therapy. Haematologica. 2015;100(7):898-904.

128. Carter BZ, Mak PY, Mak DH, Ruvolo VR, Schober W, McQueen T, et al. Synergistic effects of p53 activation via MDM2 inhibition in combination with inhibition of $\mathrm{BCl}-2$ or $\mathrm{BCr}-\mathrm{Abl}$ in $\mathrm{CD} 34+$ proliferating and quiescent chronic myeloid leukemia blast crisis cells. Oncotarget. 2015;6(31):30487-99.

129. Okabe S, Tauchi T, Tanaka Y, Ohyashiki K. Anti-leukemic effects of venetoclax on Philadelphia chromosome positive leukemia cells. Blood. 2016;128(22):5428.

130. Maiti A, Ravandi F, Cortes JE, Jabbour E, Marx K, Daver NG, et al. Venetoclax (VEN) and tyrosine kinase inhibitor (TKI) combinations in Philadelphia chromosome-positive $(\mathrm{Ph}+)$ acute myeloid leukemia (AML) and chronic myeloid leukemia myeloid blast phase (CML MBP). J Clin Oncol. 2019;37(Suppl 15):e18515.

131. Gambacorti-Passerini C, Brummendorf TH, Kim DW, Turkina AG, Masszi T, Assouline S, et al. Bosutinib efficacy and safety in chronic phase chronic myeloid leukemia after imatinib resistance or intolerance: minimum 24-month follow-up. Am J Hematol. 2014:89(7):732-42.

132. ClinicalTrials.gov. A pivotal study of HQP1351 in patients with chronic myeloid leukemia in chronic phase. https://clinicaltrials.gov/ct2/show/ NCT04126681. Accessed 20 June 2020.

133. ClinicalTrials.gov. A pivotal study of HQP1351 in patients of chronic myeloid leukemia in chronic phase with T315I mutation. https://clini caltrials.gov/ct2/show/NCT03883087. Accessed 20 June 2020.

\section{Publisher's Note}

Springer Nature remains neutral with regard to jurisdictional claims in published maps and institutional affiliations.

Ready to submit your research? Choose BMC and benefit from:

- fast, convenient online submission

- thorough peer review by experienced researchers in your field

- rapid publication on acceptance

- support for research data, including large and complex data types

- gold Open Access which fosters wider collaboration and increased citations

- maximum visibility for your research: over $100 \mathrm{M}$ website views per year

At BMC, research is always in progress.

Learn more biomedcentral.com/submissions 